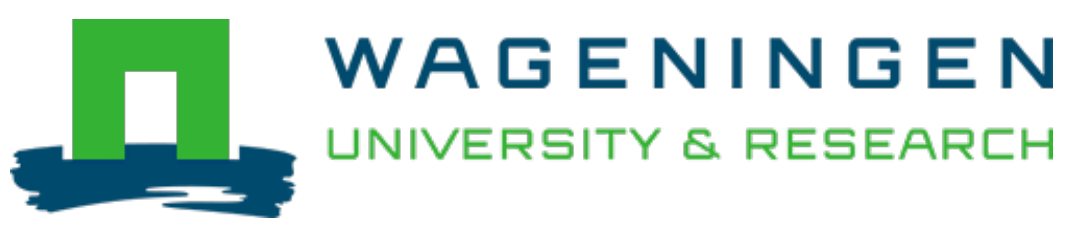

\title{
An Integrated Assessment of Climate Change Impacts and Adaptation in Maize- Based Smallholder Crop-Livestock Systems in Kenya
}

\author{
Handbook of Climate Change and Agroecosystems \\ Claessens, L.F.G.; Valdivia, R.O.; Antle, J.M.; Gummadi, S.; Kilavi, Mary et al \\ https://doi.org/10.1142/9781786348814 0002
}

This publication is made publicly available in the institutional repository of Wageningen University and Research, under the terms of article $25 \mathrm{fa}$ of the Dutch Copyright Act, also known as the Amendment Taverne. This has been done with explicit consent by the author.

Article 25 fa states that the author of a short scientific work funded either wholly or partially by Dutch public funds is entitled to make that work publicly available for no consideration following a reasonable period of time after the work was first published, provided that clear reference is made to the source of the first publication of the work.

This publication is distributed under The Association of Universities in the Netherlands (VSNU) 'Article $25 \mathrm{fa}$ implementation' project. In this project research outputs of researchers employed by Dutch Universities that comply with the legal requirements of Article $25 \mathrm{fa}$ of the Dutch Copyright Act are distributed online and free of cost or other barriers in institutional repositories. Research outputs are distributed six months after their first online publication in the original published version and with proper attribution to the source of the original publication.

You are permitted to download and use the publication for personal purposes. All rights remain with the author(s) and / or copyright owner(s) of this work. Any use of the publication or parts of it other than authorised under article $25 \mathrm{fa}$ of the Dutch Copyright act is prohibited. Wageningen University \& Research and the author(s) of this publication shall not be held responsible or liable for any damages resulting from your (re)use of this publication.

For questions regarding the public availability of this publication please contact openscience.library@wur.nl 


\title{
Chapter 2
}

\section{An Integrated Assessment of Climate Change Impacts and Adaptation in Maize-Based Smallholder Crop-Livestock Systems in Kenya}

\author{
Lieven Claessens*, ${ }^{*}$, Roberto O. Valdivia ${ }^{\ddagger}$, Sridhar Gummadi ${ }^{\S}$, Mary Kilavi ${ }^{I I}$, \\ John Rechall,**, Caleb Dickson ${ }^{\ddagger}$, and John M. Antle \\ *International Institute of Tropical Agriculture (IITA), Arusha, Tanzania \\ ${ }^{\dagger}$ Soil Geography and Landscape, Wageningen University \& Research, Wageningen, \\ the Netherlands \\ $\ddagger$ Oregon State University, Corvalllis, Oregon, USA \\ $\S$ International Crops Research Institute for the Semi-Arid Tropics (ICRISAT), \\ Nairobi, Kenya \\ II Kenya Meteorological Department, Nairobi, Kenya \\ "CGIAR Research Program on Climate Change, Agriculture and Food Security (CCAFS), \\ East Africa \\ **International Livestock Research Institute (ILRI), Nairobi, Kenya
}

\section{Introduction}

The changing climate is exacerbating existing vulnerabilities of the poorest people who depend on semi-subsistence agriculture for their survival. Sub-Saharan Africa (SSA) in particular is predicted to experience considerable negative impacts of climate change. The Intergovernmental Panel on Climate Change (IPCC) AR5 report (2014) emphasizes that adaptation strategies are essential, and these must be developed and promoted within the broader economic development policy context. Addressing adaptation in the context of small-scale, semi-subsistence agriculture in SSA raises special challenges that cannot be addressed adequately by the approaches taken thus far in most studies.

Most of the existing research has focused on impacts of climate change and adaptation in the commercial agriculture of industrialized countries. In the relatively few studies conducted in SSA, agricultural research has either focused on individual 
crops, has used aggregated data and models, or used statistical analysis too general to be useful for site-specific adaptation strategies.

One of the important constraints to carrying out this type of research is that the data demands are high, because site-specific biophysical, and socio-economic data are required, typically obtained from costly multi-year farm-level surveys. The development and application of relatively simple and reliable methods for ex ante evaluation of adaptation strategies at the household and system levels are needed to provide timely assessments of the projected impacts of climate change and feasible possibilities for adaptation (Claessens et al., 2012, 2015).

In this chapter, we describe and apply the regional integrated assessment (RIA) methodology developed by the Agricultural Model Inter-comparison and Improvement Project (AgMIP) (Rusenzweig et al., 2013; Antle et al., 2015). The methodology uses survey, experimental, and modeled data to ex ante assess impacts of climate change and adaptation on heterogeneous farm populations for a range of climate and socio-economic scenarios.

\section{Description of Farming Systems Investigated: Kenyan Maize-based Systems}

The study area covers a large area of Kenya from the coast through the central highlands to the western side of the country where maize is the major staple crop. The region is bounded by latitudes $4^{\circ} 70^{\prime} \mathrm{S}, 1^{\circ} 00^{\prime} \mathrm{N}$ and longitudes $34^{\circ} 09^{\prime} \mathrm{E}$ and $39^{\circ} 60^{\prime} \mathrm{E}$ and slopes from west to east. There are 14 synoptic weather stations within the region covering about 70 villages. Figure 1 shows the study locations and the agro-ecological regions within which they fall. Each marker on the figure denotes a village and (virtual) weather station.

The main maize growing season in the region is between March, April, May, June, and July (MAMJJ). The rainfall and temperatures across the study sites vary considerable during this season. Along the coast (low maize potential zone (MPZ)), the average MAMJJ rainfall is generally above $600 \mathrm{~mm}$. The sites in the eastern and southeastern semi-arid lowlands (low MPZ) have the lowest average seasonal rainfall, between $200 \mathrm{~mm}$ and $400 \mathrm{~mm}$. Most of the sites within the central and western highlands, the western transitional, and the western lowlands (medium MPZ) have the highest rainfall of between $800 \mathrm{~mm}$ and $1000 \mathrm{~mm}$, and in some cases, rainfall exceeds $1000 \mathrm{~mm}$. In the high MPZ, $500 \mathrm{~mm}$ to $600 \mathrm{~mm}$ is the average rainfall for most sites, however, there are some areas that receive more than $800 \mathrm{~mm}$. Within the rift valley, there are some sites at the marginal rain shadow (medium MPZ) that 


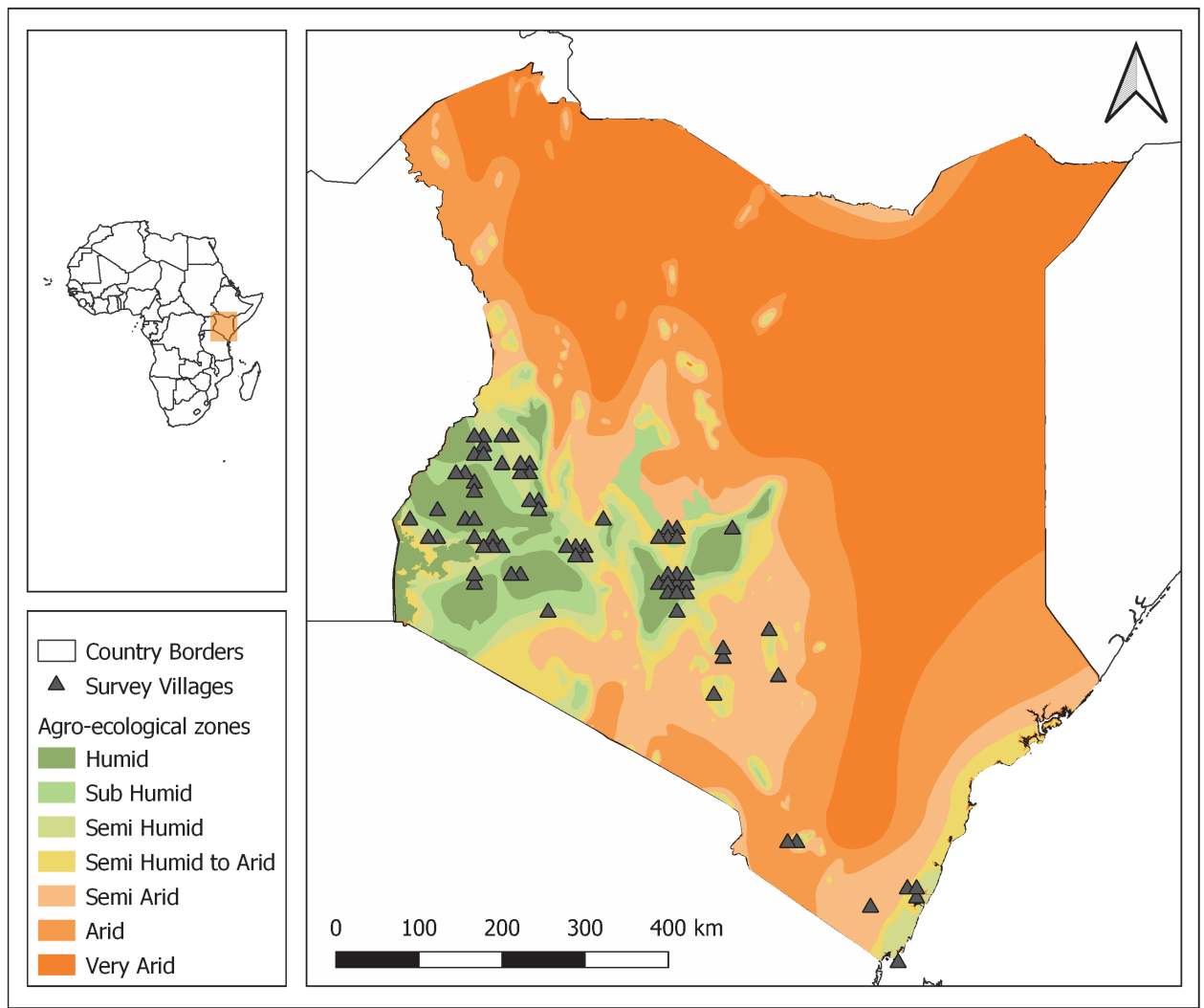

Fig. 1. Study locations, (virtual) weather stations, and agro-ecological zones in Kenya.

have a low rainfall of between $300 \mathrm{~mm}$ and $400 \mathrm{~mm}$ over the western parts of the country.

The average temperature pattern for Kenya during the MAMJJ season also exhibits differences across the country. The coastal region and the southeastern parts of the country have the highest average temperatures, above $24^{\circ} \mathrm{C}$, followed by the western parts and a swath within the southeastern region that borders the central areas. The coolest part of the country is within the rift valley where the average temperature during the growing season ranges between $15^{\circ} \mathrm{C}$ and $18^{\circ} \mathrm{C}$. The central region and the western highlands have an average temperature of between $18^{\circ} \mathrm{C}$ and $21^{\circ} \mathrm{C}$.

The farm households in these areas produce a mix of crops (e.g., maize, beans, and root and tuber crops) and livestock products (e.g., milk). Farm sizes differ across 
the regions but are generally small (1-2ha). There is some variation in input use across the MPZs; however, the agricultural systems are generally characterized by low input use. Households in the low and medium MPZs tend to receive a smaller amount of income from maize than households in the high MPZ. Other common crops in the maize-based systems are bananas, beans, cowpeas, potatoes, avocados, mangos, sweet potatoes, onions, and sukuma wiki (collard greens). These crops tend to make up a greater share of income than maize in the medium and low MPZs. Moreover, milk net returns provide a substantial amount of income and the poverty rates are lower for households with milk sales.

Average maize yields are close to $3000 \mathrm{~kg} / \mathrm{ha}$ in the high MPZ, $2500 \mathrm{~kg} / \mathrm{ha}$ in the medium MPZ, and $1300 \mathrm{~kg} / \mathrm{ha}$ in the low MPZ. The households in the high MPZ tend to have a greater share of farmland allocated to maize production $(60 \%-70 \%)$ and have higher input use than those in the other MPZs. Almost all these households use hybrid seed and, on average, apply more $\mathrm{N}$ fertilizer and have higher land preparation costs than households in the other MPZs. Hybrid use is also high in the medium MPZs and these households use more $\mathrm{N}$ fertilizer and manure than those in the low MPZs. The area allocated to maize tends to be lower on the farms in the medium MPZs compared to the other MPZs. About half of the farms in the low MPZs use hybrid maize seed and $\mathrm{N}$ fertilizer use is very uncommon.

Besides cow milk production, farms also produce and sell other livestock products such as eggs, meat, honey, hides, goat milk, wool, and manure. However, these activities tend to make up a small share of income compared to cow milk. The average number of cows is between 1 and 2 across all the MPZs. The overall herd size (total cattle) is highest in the high MPZ. Ownership of improved breed cattle is relatively rare compared to ownership of local and cross breeds. In terms of total milk production, the total production and milk yield are highest in the high MPZs and lowest in the low MPZs, on average.

\section{Key Decisions and Stakeholder Interactions}

The East African (Kenya, Tanzania, and Uganda) AgMIP team collated information on climate change and adaptation research from different sources (including relevant results from AgMIP Phase 1) for sharing with stakeholders at the national and sub-national levels. The East African team recognized that the best engagement is demand-driven (from the stakeholders). Therefore, the first step taken was to document, through desk reviews, the climate-related risks that people face, and the types of information and solutions required before engaging in face-to-face stakeholder meetings.

The stakeholders discussed ideas based on guiding questions shared by the AgMIP Stakeholder Unit. The Finance Innovation for Climate Change Fund 
(FICCF) sought more information on options for climate change adaptation in Kenya, with a focus on the roles of private sector innovation and investment, climate change policy (institutions and regulation), and societal capacity. The Makueni County officials sought more scientific information on options for climate change adaptation to enhance resilience to changing climate. This stakeholder feedback was used to inform the modeling process by the national teams.

The Climate-Smart Agriculture Component of FICCF engaged with the East African team as a follow-up to a national-level AgMIP project presentation during a meeting in April 2016. The FICCF is a component of the Department for International Development (DFID) Kenya program Strengthening Adaptation and Resilience to Climate Change in Kenya Plus (StARCK+) which aims to focus its resources in (a) catalyzing private sector innovation and investment, (b) climate change governance, focusing on stronger policy, institutional, and regulatory frameworks, and (c) enhancing capacity of civil society. The FICCF is managed by a consortium of Development Alternative Incorporated (DAI), Matrix Development Consultants, and the International Institute for Sustainable Development (IISD).

At the sub-national level, the Makueni County of Kenya, having a population of about one million people, was seeking more scientific information (case studies and recommendations) on options for climate change adaptation to help its citizens develop resilience to the changing climate. They were eager to use research findings from previous studies that were relevant to the county, in its operationalization of the 2013-2017 County Integrated Development Plan. The county passed a law that sets aside $1 \%$ of its KSh 5 billion annual development budget towards climate change adaptation. The County Climate Change Fund (CCCF) regulation passed by the Makueni County Assembly was the first of its kind in Kenya and Africa. The DFID Kenya Director Ian Mills lauded Makueni for setting the pace for other counties to follow. The East Africa AgMIP team held a meeting with Makueni County decision makers in February 2016.

\section{Data and Methods of Study}

This RIA uses data to calibrate and connect climate modeling, crop modeling, and economic modeling. The AgMIP modelling framework is applied under various scenarios to examine the intertwined impacts of climate change, socio-economic development, and adaptation on maize-based systems in Kenya. The assessment includes the use of multiple future climate scenarios: combinations of two representative concentration pathways (RCPs) and five general circulation models (GCMs). Under each climate scenario, maize yields are simulated using crop models (Decision Support System for Agrotechnology Transfer (DSSAT) and Agricultural Production Systems Simulator (APSIM)). Furthermore, both the current and future agricultural systems are modeled using crop and economic models. 
The future systems are developed under two representative agricultural pathways (RAPs). The RAPs are meant to account for the impact that development in the agricultural sector and future socio-economic conditions are expected to have on the agricultural production systems. Each RAP is associated with a shared global socio-economic pathway (SSP) and future climate (RCP) for the year 2050. The future Kenyan farming systems in each RAP are established based on information from literature, local researchers, local stakeholders, and the SSP-RCP narratives.

The analysis utilized data from a survey of Kenyan farmers representing the maize producing regions of Kenya conducted by the Tegemeo Institute (2007) to parameterize crop and economic models to represent the current production systems. These data were combined with other data from climate projections, expert data, and RAPs to parameterize future and adapted systems, using the AgMIP RIA methods (AgMIP, 2018).

The research questions in this study motivate how the impacts of climate change and adaptation are analyzed across these scenarios (see Fig. 2). Core Question 1 examines the sensitivity of current agricultural systems to climate change by
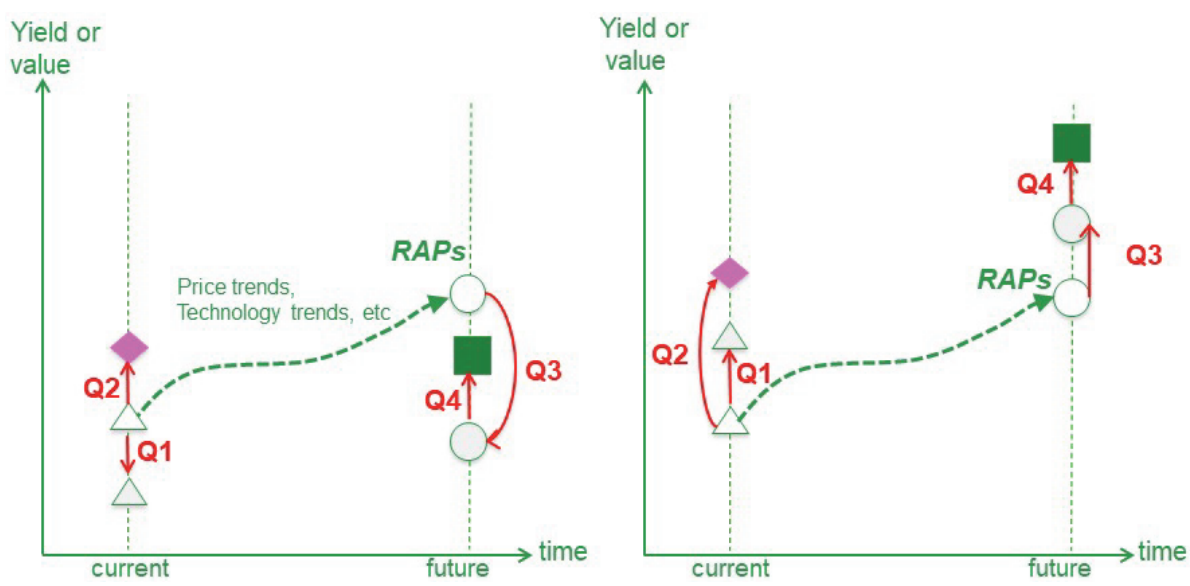

Fig. 2. How the impacts of climate change and adaptation are analyzed across these scenarios The research questions.

Notes: Q1: What is the sensitivity of current agricultural production systems to climate change? This question addresses the isolated impacts of climate changes assuming that the production system does not change from its current state.

Q2: What are the benefits of adaptation in current agricultural systems? This question addresses the benefit (e.g., economic and food security resilience) of potential adaption options to current agricultural systems given current climate.

Q3: What is the impact of climate change on future agricultural production systems? Assessment of climate impacts on the future production system, which will differ from the current production system due to development in the agricultural sector.

Q4: What are the benefits of climate change adaptations? Assessment of the benefits of potential adaptation options in the future production system. 
modeling how current production systems perform in each future climate scenario. Core Question 2 analyses the benefits of adaptation in current production systems and current climate. The next two core questions focus on the future production systems developed under each RAP. The impact of future climate scenarios on future production systems is evaluated in Core Question 3; this question differs from Core Question 1 because the crop and economic models include elements from the RAPs to model future agricultural systems. The benefits of climate change adaptation in the future are analyzed in Core Question 4. This analysis is focused on the impacts of potential adaptation options in future production systems that may offset or capitalize on climate impacts identified in Core Question 3.

\section{Climate}

\section{Historical climate series}

Daily rainfall and maximum and minimum temperatures for the period 1980-2010 for 14 synoptic weather stations spread out within the maize growing corridor were obtained from the Kenya Meteorological Department. The stations used are Mombasa, Voi, Kambi ya Mawe, Thika, Dagoretti, Embu, Nakuru, Narok, Kisii, Kakamega, Kericho, Eldoret, Kitale, and Kisumu. The data were subjected to quality control using the R-Climdex and Tamet tools to flag spurious values. Rainfall values exceeding the mean by more than three standard deviations were inspected and were only included upon confirmation from the actual observation files. Season discontinuities in both maximum and minimum temperatures beyond 10 degrees were omitted. The minimum acceptable daily temperature range was set at $3^{\circ} \mathrm{C}$. The missing data for the whole period (1980-2010) was less than $10 \%$ for each of the variables.

Bias-corrected Modern-Era Retrospective Analysis for Research and Applications (MERRA) datasets were used to fill the missing values and to replace the spurious ones. The bias correction was achieved by calculating a correction factor between each variable of the MERRA data and the corresponding observations for every month for each station and employing the factor on the MERRA data to estimate the missing values. For temperature, the bias was the difference between the MERRA values and the observations while that of rainfall was the ratio between the two datasets.

Solar radiation, vapour pressure, relative humidity dew point temperature, and wind speed values were obtained directly from the MERRA datasets. Each of the 70 village locations was assigned to the most representative weather station by taking into consideration the climatic zone, geographic distance, and elevation. The climate series of each of the crop modeling locations was estimated from the weather 
stations using differences in monthly climatology from the Worldclim datasets using the farm climate routines (AgMIP RIA Protocols).

\section{Baseline climate}

The villages have diverse climates owing to their geographical positions relative to the circulation altering orographic features, such as the Great Rift Valley, the mountains, the ocean, and inland lakes. The western parts have tri-modal seasonal rainfall distribution, i.e., March April May (MAM), June July August September (JJAS), and October November December (OND), but the central and the eastern parts have bi-modal distribution (MAM and OND). For the western and central areas, the MAM season is more significant but OND is the more important season for the eastern sector. Along the coast, the rainfall peaks in May. The growing season that was investigated is the March April May June July (MAMJJ). Along the coast (where the MS01 and MS03-MS05 sites are located), the average MAMJJ rainfall is above $600 \mathrm{~mm}$. Site MS02 is much further inland and drier $(400-600 \mathrm{~mm})$.

The eastern and southeastern lowlands (VI, TK, and MA sites) have the lowest average seasonal rainfall of between $200 \mathrm{~mm}$ and $400 \mathrm{~mm}$. Most of the sites within the central and western highlands, the western transitional, and as the western lowlands (MB, GT, KG, and KS) have the highest rainfall of between $800 \mathrm{~mm}$ and $1000 \mathrm{~mm}$ and a few receive more than $1000 \mathrm{~mm}$. The average rainfall for some of the high MPZs (NK and LD01-04) is between $500 \mathrm{~mm}$ to $600 \mathrm{~mm}$ except the KS sites that have above $800 \mathrm{~mm}$. Within the rift valley there are some sites at the marginal rain shadow (NK05-09) that have a lower rainfall of between $300 \mathrm{~mm}$ and $400 \mathrm{~mm}$ over the western parts of the country (Fig. 3).

A summary of the average temperature and precipitation for the region during the baseline period is provided in Table 1 .

\section{Selection of representative GCMs and generation of future GCM scenarios}

In order to capture the whole range of plausible future scenarios for the region, downscaled scenarios from all the 29 CIMP5 models were generated using the run_agmip_simple_mandv (AgMIP Climate Scenario Guide) script to simulate both the mean and variability of future climates. Plots of temperature and precipitation changes for each of the 14 weather stations were made for the main growing season (MAMJJ) for RCPs 4.5 and 8.5 for the mid-century period. Deviations of each of the models from the median changes were used to categorize them as either cool and wet, cool and dry, hot and wet, hot and dry, or average. The five categories are illustrated in the five quadrants in Fig. 4 for two of the stations under RCP 8.5.

A comparison of the plots from all the 14 weather stations was made in order to determine the particular models that were consistent within the same categories 


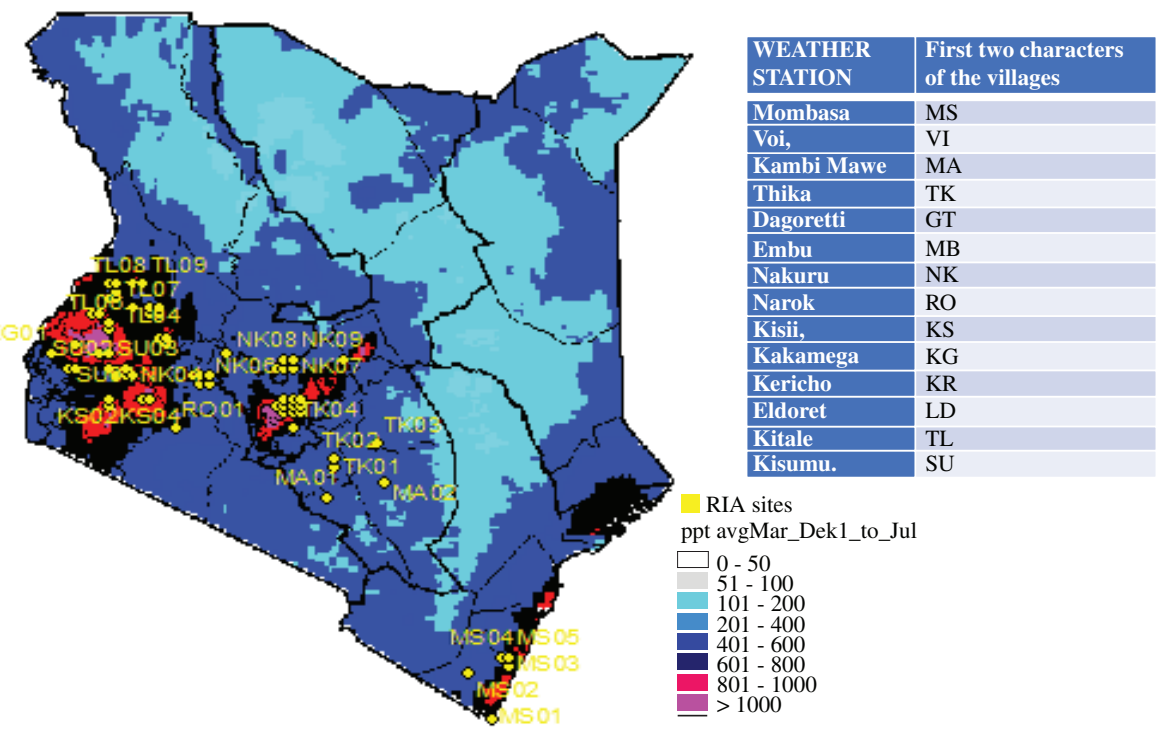

Fig. 3. The average MAMJJ rainfall for the region.

Table 1. Mean temperature and precipitation for the weather stations from 1980 to 2010.

\begin{tabular}{|c|c|c|c|c|c|c|c|}
\hline Site & $\begin{array}{c}\text { Station } \\
\text { Used }\end{array}$ & Type & $\begin{array}{c}\text { Crop } \\
\text { Species }\end{array}$ & $\begin{array}{l}\text { Growing } \\
\text { Months }\end{array}$ & $\begin{array}{c}\text { Mean GS } \\
\text { Temperature } \\
\text { (C) }\end{array}$ & $\begin{array}{c}\text { Total GS } \\
\text { Precipitation } \\
(\mathbf{m m})\end{array}$ & $\begin{array}{c}\text { Total GS } \\
\text { Rainy Days } \\
\text { (\#) }\end{array}$ \\
\hline Dagoretti & GT01 & Baseline & Maize & MAMJJ & 15.6 & 517.7 & 54 \\
\hline Kakamega & KG01 & Baseline & Maize & MAMJJ & 21.9 & 528.3 & 99 \\
\hline Kisii & KS01 & Baseline & Maize & MAMJJ & 21.8 & 1392.6 & 98 \\
\hline Eldoret & LD01 & Baseline & Maize & MAMJJ & 19.3 & 437.4 & 71 \\
\hline Kambi Mawe & MA01 & Baseline & Maize & MAMJJ & 22.1 & 399.9 & 22 \\
\hline Embu & MB01 & Baseline & Maize & MAMJJ & 18.6 & 1168.4 & 67 \\
\hline Mombasa & MS01 & Baseline & Maize & MAMJJ & 26.2 & 635.3 & 70 \\
\hline Nakuru & NK01 & Baseline & Maize & MAMJJ & 22.2 & 504.9 & 76 \\
\hline Kericho & $\mathrm{RC} 01$ & Baseline & Maize & MAMJJ & 20.1 & 952.4 & 100 \\
\hline Narok & RO01 & Baseline & Maize & MAMJJ & 16.8 & 352.3 & 38 \\
\hline Kisumu & SU01 & Baseline & Maize & MAMJJ & 23.5 & 573 & 72 \\
\hline Thika & TK01 & Baseline & Maize & MAMJJ & 19.7 & 366.3 & 55 \\
\hline Kitale & TL01 & Baseline & Maize & MAMJJ & 25 & 452.2 & 89 \\
\hline Voi & VI01 & Baseline & Maize & MAMJJ & 23.3 & 183.3 & 25 \\
\hline
\end{tabular}

throughout the region for each of the RCPs. For both RCPs 4.5 and 8.5, the following models were found to be consistently cool/wet, average, hot/wet, and hot/dry respectively: CESM1-BGC, MPI-ESM-LR, IPSL-CM5A-MR, and CMCC-CMS. For the cool/dry scenario, inmcm4 was more consistent under RCP 4.5 and FGOALS-g2 
Median Quartile Distribution of Temperature and Precipitation Change

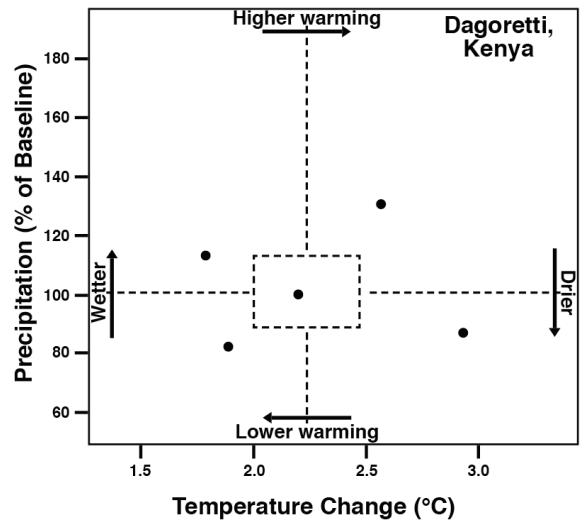

(a)
Median Quartile Distribution of Temperature and Precipitation Change

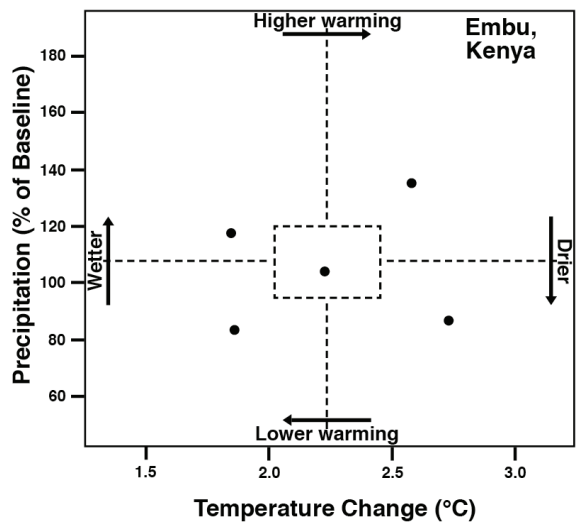

(b)

Fig. 4. A plot of deviation from the median changes of the CMIP5 GCMs for the mid-century RCP 8.5 for (a) Dagoretti and (b) Embu.

for RCP 8.5. Scenarios from these GCMs were downscaled for all the 70 integrated assessment locations and were used as inputs for the crop models. Figure 5 shows three examples of rainfall and temperature projections for the five models. Table 2 provides a summary of the projected changes for the broad areas represented by the 14 weather stations. All changes are relative to the baseline mean values.

All the models predict a warmer future compared to the current climate. In addition, the future scenarios are warmer under RCP 8.5 than RCP 4.5. Across the region, the GCMs project a minimum temperature change of $0.6^{\circ} \mathrm{C}$ and a maximum change of $2.5^{\circ} \mathrm{C}$ with RCP 4.5 during the mid-century period. Under RCP 8.5 , the range of temperature change is projected between $1.1^{\circ} \mathrm{C}$ and $3.4^{\circ} \mathrm{C}$. The projected increase in temperature is lowest at the coast and increases westward and is therefore highest at the sites near the Kenya-Uganda border. Under the RCP 4.5 scenario, the change in precipitation is projected to be between $-19 \%$ and $35 \%$. The change in precipitation under RCP 8.5 is $35 \%$ in the wettest scenario and $-25 \%$ in the driest scenario.

\section{Crops}

Crop model set-up

For the main season crop modeled (planting in April, harvest in late summer), substantial variations in sowing dates and $\mathrm{N}$ fertilizer applications were observed among the survey farms. The sowing window mostly ranged between the first and 
(a) RCP4.5 Mid-Century Temperature Scenarios for Five GCMs (Dagoretti)

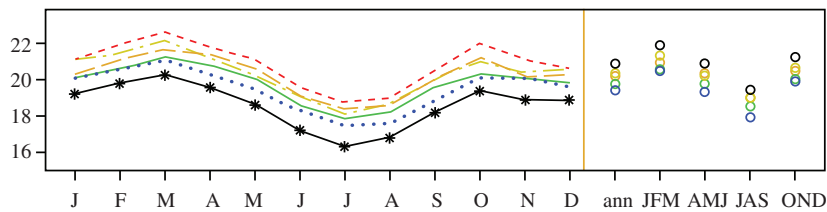

RCP4.5 Mid-Century Precipitation Scenarios for Five GCMs (Dagoretti)

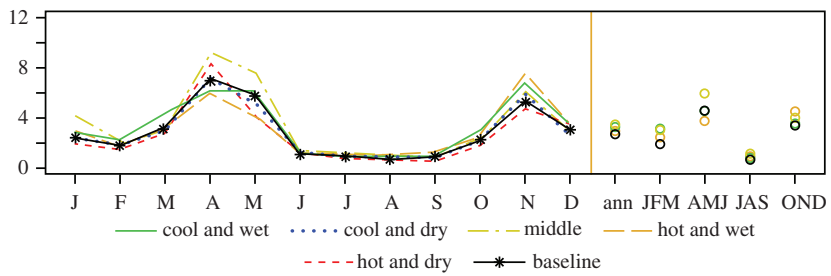

(b) RCP4.5 Mid-Century Temperature Scenarios for Five GCMs (Kitale)

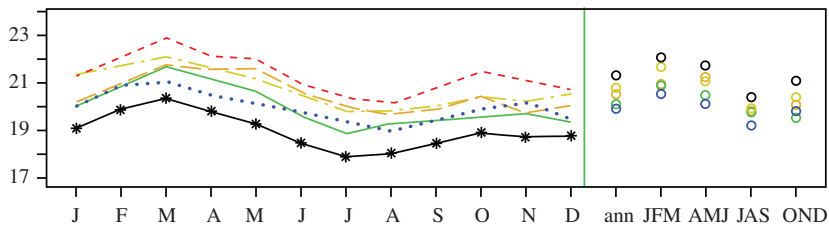

RCP4.5 Mid-Century Precipitation Scenarios for Five GCMs (Kitale)

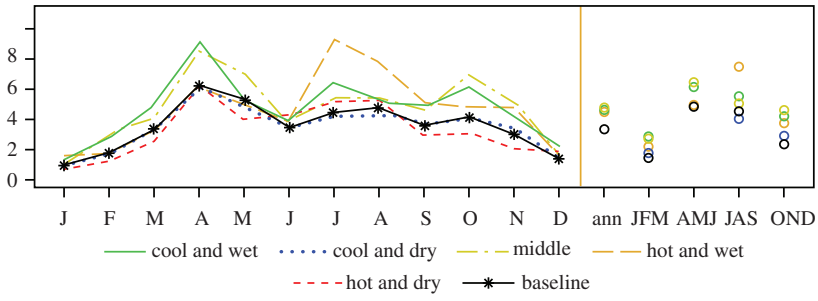

(c) RCP4.5 Mid-Century Temperature Scenarios for Five GCMs (Mombasa)

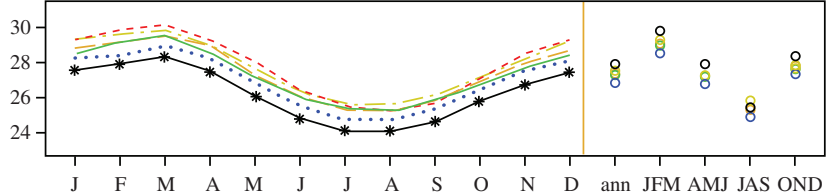

RCP4.5 Mid-Century Precipitation Scenarios for Five GCMs (Mombasa)

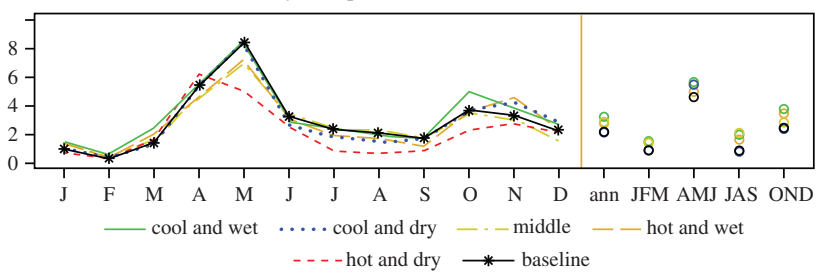

Fig. 5. Rainfall and temperature projections for the five climate models for RCP 4.5 for (a) Dagoretti, (b) Kitale, and (c) Mombasa. 
Table 2. Summary of projected changes for the 14 stations used.

\begin{tabular}{|c|c|c|c|c|c|c|c|}
\hline Site & Crop & $\begin{array}{l}\text { Historical } \\
\quad\left({ }^{\circ} \mathrm{C}\right)\end{array}$ & $\begin{array}{c}\text { RCP4.5 } \\
\text { Coolest } \\
\Delta \mathrm{T}\left({ }^{\circ} \mathrm{C}\right)\end{array}$ & $\begin{array}{c}\text { RCP8.5 } \\
\text { Warmest } \\
\Delta \mathrm{T}\left({ }^{\circ} \mathrm{C}\right)\end{array}$ & $\begin{array}{c}\text { Historical } \\
\text { Precipitation } \\
(\mathbf{m m})\end{array}$ & $\begin{array}{c}\text { RCP8.5 } \\
\text { Driest } \Delta \mathbf{P} \\
(\%)\end{array}$ & $\begin{array}{c}\text { RCP4.5 } \\
\text { Wettest } \Delta \mathbf{P} \\
(\%)\end{array}$ \\
\hline Dagoretti & Maize (MAMJJ) & 15.6 & 0.9 & 3.2 & 517.7 & -24.6 & 24 \\
\hline Kakamega & Maize (MAMJJ) & 21.9 & 0.9 & 3.4 & 528.3 & -13.2 & 35.1 \\
\hline Kisii & Maize (MAMJJ) & 21.8 & 0.9 & 3.2 & 1392.6 & -22.4 & 30.7 \\
\hline Eldoret & Maize (MAMJJ) & 19.3 & 0.9 & 3.4 & 437.4 & -13.3 & 35.1 \\
\hline Kambi ya Mawe & Maize (MAMJJ) & 22.1 & 0.8 & 3.0 & 399.9 & -13.8 & 35.1 \\
\hline Embu & Maize (MAMJJ) & 18.6 & 0.9 & 3.0 & 1168.4 & -24.6 & 19.9 \\
\hline Mombasa & Maize (MAMJJ) & 26.2 & 0.6 & 2.3 & 635.3 & -18.9 & 25.6 \\
\hline Nakuru & Maize (MAMJJ) & 22.2 & 0.9 & 3.2 & 504.9 & -24.6 & 30.7 \\
\hline Kericho & Maize (MAMJJ) & 20.1 & 0.9 & 3.4 & 952.4 & -13.3 & 35.2 \\
\hline Narok & Maize (MAMJJ) & 16.8 & 0.9 & 3.2 & 352.3 & -22.4 & 30.7 \\
\hline Kisumu & Maize (MAMJJ) & 23.5 & 0.9 & 3.2 & 573.0 & -22.4 & 30.7 \\
\hline Thika & Maize (MAMJJ) & 19.7 & 0.9 & 3.0 & 366.3 & -24.6 & 14.8 \\
\hline Kitale & Maize (MAMJJ) & 25.0 & 0.9 & 3.4 & 452.2 & -13.3 & 35.3 \\
\hline Voi & Maize (MAMJJ) & 23.3 & 0.8 & 2.8 & 183.3 & -14.4 & 25.7 \\
\hline
\end{tabular}


third week of April. Variation in $\mathrm{N}$ fertilizer application was also observed and ranged between $0 \mathrm{Nkg} / \mathrm{ha}$ and $80 \mathrm{Nkg} / \mathrm{ha}$. Crop management parameters used in setting simulations for individual farms were derived from the survey conducted during 2007-2008. The survey was designed to capture, among other things, cultivars used, planting date, amount of seed used, fertilizer and manure applied during the 2007 crop season, and harvested yield. Farmers in the region used a large number of crop varieties, and for many of these varieties, the required data to derive model parameters are not available. In these cases, a similar cultivar was used to parameterize the crop models. The identification of this cultivar was based on its growth duration and yield potential. The Katumani cultivar was used as local variety.

Soil data were collected from soil survey reports and major soil formations in the target region were identified using available soil maps (AfSIS/ISRIC). Representative soil profiles for Kenya for each of the major soil types were then identified from the soil survey reports. Other soil data required as inputs to crop models were derived from the Global High-Resolution Soil Profile Database for Crop Modeling Applications (IRI, MSU, and IFPRI, 2015).

Simulations used the amount of seed reported by farmers, combined with secondary data to estimate the plant population at sowing. Previous studies in the region have indicated that the plant population on farmer fields varied from about 20,000 plants/ha to 60,000 plants/ha depending on the potential of the area to grow maize and the inputs used. Accordingly, a plant population of 20,00030,000 plants $/$ ha was assigned to farmers using seed rates lower than $15 \mathrm{~kg} / \mathrm{ha}$, 40,000 plants/ha for those using seed rates of $15-20 \mathrm{~kg} / \mathrm{ha}$, and $50,000-60,000$ plants/ha for those using more than $20 \mathrm{~kg} / \mathrm{ha}$ of seed rates.

The DSSAT and APSIM crop models were calibrated and used to simulate yields for each farm with observed crop variety and fertilizer applications. Yields in the low productivity zone were about $40 \%-60 \%$ lower than in the medium and high zones (Table 3 ). The average simulated yields tended to be lower than the observed yields in the low productivity zones, with DSSAT under-predicting more than APSIM. Simulations were more similar in the medium and higher productivity zones.

\section{Model sensitivity response to $\mathrm{CO}_{2}$, temperature, rainfall, and $\mathrm{N}$ fertilization}

Maize sensitivity to $\mathrm{CO}_{2}$, temperature, rainfall, and $\mathrm{N}$ fertilization (CTWN) in Kenya was evaluated separately for each of the MPZs (Fig. 6). In the high MPZ, DSSAT maize showed a modest response to $\mathrm{CO}_{2}$, but APSIM showed almost no response to $\mathrm{CO}_{2}$, with neither result surprising for maize, a $\mathrm{C} 4 \mathrm{crop}$. The maize response to $\mathrm{N}$ fertilization in the high MPZ starts out similarly for both DSSAT and APSIM, indicating that stable carbon pools were calibrated well for both models. However, the overall higher yield of DSSAT over APSIM at high N levels shows differences in 
Table 3. Observed and simulated average yields for survey fields (CM0) and baseline climate per farm (averaged yield over 30 weather years, CM1).

\begin{tabular}{lccccrr}
\hline & & \multicolumn{2}{c}{ APSIM } & & \multicolumn{2}{c}{ DSSAT } \\
Strata & Observed & CM0 & CM1 & & CM0 & CM1 \\
\hline Low & 1287 & 1170 & 1109 & & 859 & 842 \\
Low-milk & 1340 & 1194 & 1151 & & 943 & 918 \\
Medium & 2373 & 2197 & 2099 & & 2014 & 1889 \\
Medium-milk & 2729 & 2352 & 2270 & & 2162 & 2072 \\
High & 2740 & 2812 & 2638 & & 2358 & 2246 \\
High-milk & 3136 & 3263 & 3019 & 2911 & 2788 \\
\hline
\end{tabular}

calibration of genetic coefficients for high yield potential. Maize response to rainfall for both the crop models indicates that the rainfall is generally quite adequate, with yield being only slightly improved at $125 \%$ rainfall, in the high MPZ. While yield is very low for both models at 25\% rainfall (as expected), APSIM and DSSAT differ in response to rainfall at $50 \%$ to $75 \%$ of normal rainfall. In terms of temperature, APSIM and DSSAT show different response patterns, particularly in the high MPZ. These responses are associated with different parameterizations of the temperature parameters for rate of grain growth. The parameterization differences are the primary reasons for APSIM being more sensitive to lower temperatures during grain filling and DSSAT being more sensitive at higher temperatures. Another factor is the different temperature parameterization for soil organic $\mathrm{C}$ mineralization in the two models.

For the medium MPZs and under high $\mathrm{N}$ fertilization, DSSAT showed a modest response to rising $\mathrm{CO}_{2}$, but APSIM showed no response. Under low $\mathrm{N}$ fertilization neither model showed response to $\mathrm{CO}_{2}$, again not surprising for a $\mathrm{C} 4$ crop. The overall higher yield for DSSAT than for APSIM reflects different calibration of genetic coefficients for the two models. DSSAT shows higher yield response to $\mathrm{N}$ than above APSIM at nearly all $\mathrm{N}$ fertilizer levels. Simulated response to rainfall for the medium MPZs suggests that rainfall at ambient average is not limiting yield in this region, and that higher rainfall can cause reduction in yield because of leaching of $\mathrm{N}$ from the soil. At less than average ambient rainfall, yield can be limited.

The medium potential site shows similarly strong differences in temperature response between the crop models as shown at the high potential site. The small shift in the pattern is probably related to the fact that the medium potential site is somewhat warmer than the high potential site, with rising temperature decreasing maize yield of DSSAT (which has highest yield at ambient) and increasing yield of APSIM up to $+2^{\circ} \mathrm{C}$. These differential responses are associated with different 

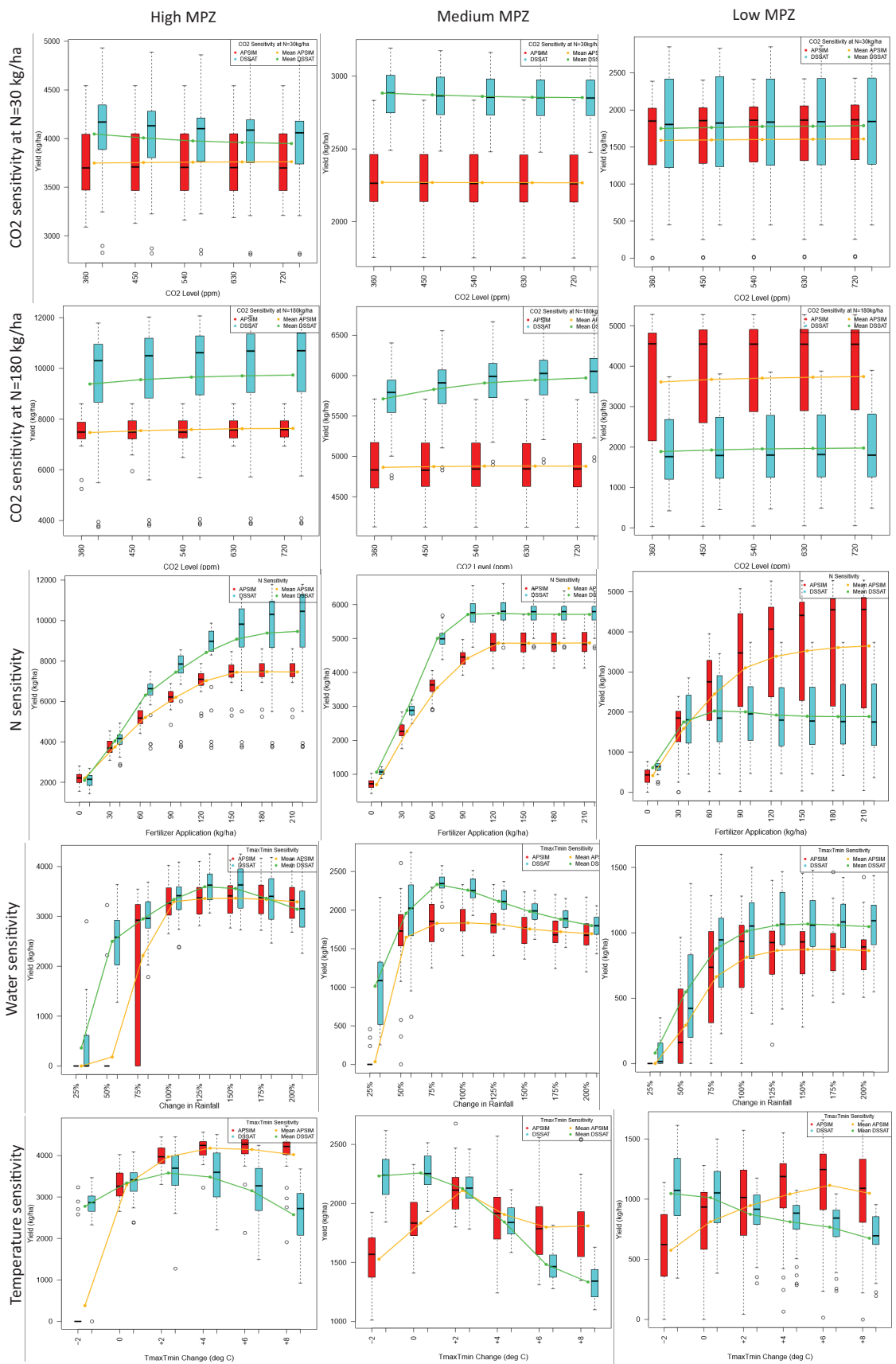

Fig. 6. Model sensitivity response to CTWN for high, medium, and low Maize Potential Zones (MPZs). The APSIM and DSSAT models show substantially different responses to $\mathrm{CO}_{2}, \mathrm{~N}$ fertilizer, and temperature across all the zones. 
parameterization of the two maize models, with major differences in the temperature parameters for rate of grain growth and minor differences in the temperature parameterization for radiation use efficiency (RUE).

We conclude that the models differ substantially in response to $\mathrm{CO}_{2}$, temperature, and $\mathrm{N}$ fertilization. This case illustrates the need for a larger multi-model ensemble to address the apparent large uncertainty in maize yield response to climate changes and adaptations involving management changes such as increased $\mathrm{N}$ use. However, due to implementation challenges for APSIM at this large number of sites, it was not possible to resolve these differences. In addition, other computational problems were encountered at some sites where zero or low $\mathrm{N}$ applications were observed. Comparisons of these results to others in the literature led the research team to conclude that the DSSAT results were likely to be more reliable at the time the RIA economic analyses had to be implemented, so only the DSSAT results were used. However, these results for the crop model simulations emphasize the need for caution in interpreting the simulated outcomes.

\section{Economics}

The Trade-off Analysis Model for Multi-Dimensional Impact Assessment (TOAMD) model is used for the economic modeling in this study. This model estimates the distribution of economic impacts of climate change and technology adoption (Antle, 2011). For Core Questions 1 and 3, climate change impacts are estimated by comparing the distribution of farm net returns under current climate to the distribution of farm net returns under future climate. The model estimates the percentage of households vulnerable to climate change (i.e., the percentage of households with lower farm net returns in future climate), net impact on mean farm net returns, change in per capita income, and change in poverty rate.

For Core Questions 2 and 4, the impacts of adaptation and the adoption rate are estimated by comparing the distribution of farm net returns without adaptation to the distribution with adaptation. At the predicted adoption rate, the changes in farm net returns, per capita income, and poverty are also quantified by the TOA-MD model. Additionally, this model allows for examination of sub-populations of farms and the aggregate population. In this assessment, farms are stratified based on their maize agroecology (high, medium, and low potential) and whether or not they sell milk. The economic impacts of climate change and adaptation are estimated for each of the resulting six strata.

Each Core Question requires the parameterization of farm net returns for two systems, following the AgMIP methods developed for RIAs (AgMIP, 2018). In Core Questions 1 and 2, the current production system under the current climate is parameterized using statistics from the household survey data. For Core Question 1, the 
current production system under future climate is parameterized using crop model results based on current management and future climate scenarios. These crop model results are used in conjunction with the AgMIP relative yield method to calculate the distribution of farm net returns. Similarly, for Core Question 2, the crop model is used to estimate the impact of adaptation on maize net returns. This question also requires the parameterization of changes in milk production, which are not modeled explicitly. These changes are parameterized using literature and information from the survey data.

Core Questions 3 and 4 require the farm net return distributions for the future farming systems of Kenya. The current production systems are scaled into the future using trends for key variables (e.g., prices, yields, and costs) based on the RAP narratives and global economic model predictions from literature. These trends are applied to all farms in the data. The result provides an approximation of the distribution of farm net returns under each RAP without climate change. Using crop model simulations based on future management, the impact of climate change on yields is predicted by simulating maize under current and future climate. The relative yield method is applied, using the crop model results, to parameterize the farm net return distribution with climate change. These distributions on future farm net returns with and without climate change are used in the Core Question 3 analysis. For Core Question 4, the crop model is used to estimate the impact of adaptation on future maize net returns for each climate scenario. Like Core Question 2, this question parameterizes changes in milk production using literature and information in the data; however, this analysis differs from Core Question 2 because it also incorporates RAP-specific trends.

\section{Description of survey data}

Table 4 shows summary statistics of the survey data across strata. The income and net returns are shown in 2007 values and the poverty rates are calculated based on a US $\$ 1.25 /$ person/day poverty line using the 2007 exchange rate between KSh and US\$ (Central Bank of Kenya, 2017). In this case, the exchange rate is $67.47 \mathrm{KSh} / \mathrm{US} \$$ and the poverty line is $2565.14 \mathrm{KSh}$ person/month. ${ }^{1}$ The $2007 \mathrm{val}-$ ues are used as these were judged to best represent the base period for the climate impact assessments from the available data.

\footnotetext{
${ }^{1}$ The TOA-MD model predicts a poverty rate of $54.2 \%$ aggregated across all strata using this poverty line (not shown in Table 4). In an assessment of poverty and inequality in Kenya, a World Bank (2009) study calculated a rural poverty line of $1562.18 \mathrm{KSh} /$ adult equivalent/month based on the costs of 2250 calories per day and basic non-food necessities, and the rural headcount poverty in 2007 Kenya is reported as 38\%. For the AGMIP RIA of maize-based systems in Kenya, the TOA-MD model predicts the aggregate poverty rate is $33.7 \%$ using the World Bank poverty line. The poverty line used in this study can be considered as an income level that exceeds subsistence.
} 
Table 4. Summary statistics of farm survey data, Kenya.

\begin{tabular}{lcccccc}
\hline Strata & Low & $\begin{array}{c}\text { Low- } \\
\text { milk }\end{array}$ & Medium & $\begin{array}{c}\text { Medium- } \\
\text { milk }\end{array}$ & High & $\begin{array}{c}\text { High- } \\
\text { milk }\end{array}$ \\
\hline \# Observations & 165 & 73 & 142 & 259 & 65 & 170 \\
HH size & 5.0 & 4.8 & 4.8 & 4.5 & 5.8 & 5.5 \\
Farm Size (ha) & 1.6 & 2.1 & 1.1 & 1.3 & 1.2 & 1.9 \\
Off-farm income (KSh) & 70,216 & 87,125 & 44,749 & 63,343 & 49,118 & 76,464 \\
Maize net returns (KSh) & 6246 & 7497 & 5433 & 5893 & 18,511 & 28,613 \\
Other crop net returns (KSh) & 14,648 & 23,550 & 36,072 & 53,032 & 9658 & 20,632 \\
Milk net returns (KSh) & - & 15,199 & - & 14,143 & - & 19,315 \\
Non-dairy net returns (KSh) & 1104 & 3135 & 2054 & 1940 & 3575 & 3803 \\
Poverty without CC* (\%) & 65.5 & 46.4 & 67.7 & 39.3 & 80.1 & 47.9 \\
Maize Yield (kg/ha) & 1287.3 & 1340.4 & 2373.4 & 2728.7 & 2739.8 & 3136.3 \\
Maize area proportion & 0.4 & 0.4 & 0.3 & 0.3 & 0.7 & 0.6 \\
Maize area (ha) & 0.7 & 0.8 & 0.3 & 0.3 & 0.8 & 1.2 \\
Proportion using hybrid & 0.34 & 0.47 & 0.74 & 0.85 & 0.85 & 0.95 \\
Seed cost (KSh/ha) & 244.4 & 286.1 & 1086.4 & 1354.1 & 1318.3 & 1291.7 \\
N fertilizer (kg/ha) & 1.6 & 4.0 & 19.2 & 22.8 & 26.2 & 29.3 \\
Manure (kg/ha) & 600.3 & 1512.7 & 1492.9 & 3636.5 & 151.1 & 236.2 \\
Land prep cost (KSh/ha) & 1797.3 & 1384.7 & 1503.7 & 2033.2 & 2779.3 & 3243.8 \\
Maize price (KSh/kg) & 11.9 & 12.3 & 11.8 & 11.4 & 10.8 & 10.8 \\
Cows & - & 1.4 & - & 1.3 & - & 1.8 \\
Total herd (cattle) & - & 3.9 & - & 3.0 & - & 6.6 \\
Grade herd (cattle) & - & 0.1 & - & 0.5 & - & 0.4 \\
Cross herd (cattle) & - & 1.0 & - & 1.6 & - & 4.6 \\
Milk production (lt/farm) & - & 975.11 & - & 1949.90 & - & 2971.36 \\
Milk per cow (lt) & - & 819.00 & - & 1564.33 & - & 1704.81 \\
Feed cost per animal (KSh) & - & 289.04 & - & 2162.81 & - & 832.19 \\
Milk price (KSh/Lt) & - & 27.44 & - & 18.38 & - & 16.12 \\
\hline & & & & & & \\
\hline
\end{tabular}

Note: *Estimated with TOA-MD.

Source: Tegemeo (2007) farm survey data.

Farm sizes differ across the strata but are generally small. Households in the low and medium MPZs tend to receive a smaller amount of income from maize than households in the high MPZ. The RIA analysis of Kenyan maize-based systems aggregates all crops other than maize into the other crops activity. Within the sample, the most common crops in this activity are bananas, beans, cowpeas, potatoes, avocados, mangos, sweet potatoes, onions, and sukuma wiki. Table 4 shows that other crops tend to make up a greater share of income than maize in the medium and low MPZs. Moreover, milk net returns provide a substantial amount of income and poverty rates are lower in the strata with milk sales. These statistics indicate that households are generally diversified across the maize-based systems in Kenya.

The households in the high MPZ tend to have a greater amount of area allocated to maize production and have higher input use than those in the other 
MPZs. Specifically, almost all of these households use hybrid seed and, on average, these households apply more $\mathrm{N}$ fertilizer and have higher land preparation costs than households in the other MPZs. Hybrid use is also high in the medium MPZs and these households use more $\mathrm{N}$ fertilizer and manure than those in the low MPZs. In fact, they use more manure than households in the high MPZs, too. The area allocated to maize tends to be lower on the farms in the medium MPZs compared to the other MPZs. Looking to the low MPZs, less than half the households use hybrid maize seed and $\mathrm{N}$ fertilizer use is very uncommon.

Households also produce several livestock products. Milk is produced and sold by households in each MPZ. Moreover, households sell eggs, honey, hides, goat milk, wool, and manure as well. The latter are characterized as non-dairy activities. This analysis focuses on milk production due to the size of its contribution to household income. Table 4 shows information on household herds and milk production across the milk strata. The average number of cows is between 1 and 2 across the strata. The overall herd size (total cattle) is highest in the high MPZ. The average number of grade (improved) breed cattle is less than 1; meanwhile, ownership of crossbreeds is much higher, as each of the MPZs has an average value above 1 animal and the high MPZ has an average of 4.6. All other animals in the herd are local breeds. In terms of total milk production, the total production and the milk yield are highest in the high MPZ and lowest in the medium and low MPZs, on average. The feed cost per animal is highest in the medium MPZs followed by the high and low MPZs, respectively. This value only accounts for purchased feed and does not represent grazing or own-produced feed.

\section{Representative Agricultural Pathways (RAPs)}

RAPs are used to characterize future agricultural systems in the AgMIP methods for RIAs (AgMIP, 2018). Valdivia et al. (2015) identify five RAPs that span a two-dimensional space between economic and environmental dimensions of sustainability. Each RAP is associated with a different shared SSP and plausible level of emissions for the year 2050 (O'Neill et al., 2015; Valdivia et al., 2015).

In this analysis, two RAPs are used to study future maize-based systems in Kenya. The first RAP is referred to as RAP 4 and is associated with RCP 4.5 and SSP1. The SSP1 is characterized by inclusive global development that emphasizes human well-being and environmental awareness at the expense of faster long-run economic growth. In this pathway, there is large investment in environmental technologies, resource and energy efficiency, and improvement in environmental conditions. Due to these characteristics, this sustainability pathway presents low challenges to climate change mitigation and adaptation. 
The second RAP developed in this study, RAP 5, represents a future with high emissions (RCP 8.5) and unsustainable high growth that comes at the expense of the environment (SSP3). International fragmentation and competition between nations are key elements of this SSP. Poor international collaboration leads countries to focus on national concerns, leading to trade barriers and favorable policies for local resources and agricultural markets. Resource degradation increases over time because environmental issues are not a priority for international policy. Moreover, dependence on fossil fuels continues and there is lack of investment in energy and resource efficiency, culminating in poor progress towards sustainability and high challenges to both mitigation and adaptation.

RAPs 4 and 5 are developed based on these RCPs and SSPs to characterize future pathways for farmers in Kenya. RAP 4 represents "Safi Kenya" (the Greener Kenya) and RAP 5 represents "Jua Kali Kenya" (Haphazard Kenya).

\section{RAP 4: Safi Kenya - The Greener Kenya}

Under RAP 4, Kenya has implemented, with relative success, Vision 2030 focusing on meeting the Millennium Development Goals and the Sustainable Development Goals (MDGs and SDGs). Increased investment in technologies that are environmentally friendly has helped the country achieve a sustainable pathway. However, economic growth has slowed as the main investments are focused on public services, such as health, education, and clean energy. Policy changes and infrastructure improvements facilitate the development of markets and availability of agricultural inputs, leading to higher farm incomes. Farms become more diversified and less dependent on maize; there is increased crop-livestock integration and off-farm income. Moreover, household sizes are smaller, while farm sizes are larger.

In the agro-ecological zones that have the highest potential for maize production (high and medium MPZs), maize yields increase as a result of increased use of mineral fertilizers, manure (produced on farm), and improved maize varieties. Productivity is also improved by extension, education, and information available to farmers. These changes are accompanied by decreases in fertilizer prices, increases in seed prices, increases in labour wages, and increases in mechanization costs. There are also a number of changes in livestock production due to government investment in infrastructure for the livestock and dairy sectors. Households increase their herd sizes (including more improved breeds) and implement improved management practices, such as using more concentrates for feed. This leads to higher milk yields and higher production costs. Moreover, due to market development, milk prices increase.

The areas of Kenya that have low agro-ecological potential for maize experience different changes in RAP 4. The milk-selling farms decrease their reliance on maize 
and focus more on milk production. The proportion of land area currently allocated to maize is decreased in order to increase the area of Napier grass and pastures. On the remaining maize land, these households institute similar improved management practices as those discussed above.

\section{RAP 5: Jua Kali Kenya - Haphazard Kenya}

Kenya follows a more positive economic development trajectory in RAP 5 than in RAP 4. Proposed agricultural interventions and policies outlined in Vision 2030 have not been fully implemented. The government has an aggressive policy to promote the industry and services sectors and there is low investment in sustainable agricultural policies. Import barriers are in place and lead to increases in prices of imported goods, including mineral fertilizer. Low investment in health and education contributes to an increase in inequality. High population growth increases the pressure on agricultural land with the consequences of unsustainable agricultural intensification and negative environmental effects. Moreover, farms become smaller in some areas while consolidation occurs in other areas.

In the high and medium MPZs, farms increase their proportion of maize area compared to the current systems. Maize yields increase due to similar management improvements as in RAP 4, except production occurs with more adverse environmental outcomes. For example, farms use less organic fertilizer and less soil conservation techniques compared to RAP 4, which results in soil degradation. Similar to farm size, average herd sizes do not change compared to current systems, but there is increased variation as some farms increase their herds, while others decrease. Milk yields improve due to improved management and breeding, which leads to increased production costs as well. Moreover, milk price increases for similar reasons as in RAP 4, but to a lesser extent. There is a lower degree of crop-livestock integration than in RAP 4, as well. Households do not use the outputs from livestock activities (e.g., manure) as productive inputs in crop activities (and vice versa) to the same extent as in RAP 4.

In the areas with low maize potential, milk-selling farms allocate land to Napier grass and pastures, but to a lesser degree than in RAP 4. Maize production systems and milk production systems are similar to RAP 4 but with increased soil degradation and less crop-livestock integration, resulting in lower manure use. In addition, milk prices do not increase to the same degree as in RAP 4 due to lower market development.

\section{Potential adaptation packages}

In Core Question 2, which is analyzed in the context of current agricultural systems, a technological intervention is designed to increase maize yields across all MPZs 
in Kenya. In each MPZ, $\mathrm{N}$ fertilizer and manure use are increased. A policy intervention is required to incentivize increased usage of fertilizer. This intervention is represented by a subsidy that lowers the prices farmers pay for commercial fertilizers DAP and CAN by $25 \%$. Access to fertilizers is also improved due to investment in infrastructure and lowering transactions costs associated with participating in fertilizer markets. The technological intervention also includes the basic elements of the East Africa Dairy Development (EADD) project that includes donating one improved breed milking cow to every farm (EADD 2013, 2014). Technical assistance programs are put in place to improve feeding strategies for milking cows as well. These improved strategies are instituted for all the cows on each farm (preexisting and new). Additionally, the manure application is increased by $1000 \mathrm{~kg} / \mathrm{ha}$ as a result of all farms receiving an additional cow. This is based on the approximate amount of manure produced by a cow each month (Valdivia, 2016).

The Core Question 4 technological intervention for Kenya is consistent with that of Core Question 2; however, it is tailored to the future maize-based systems in a world with climate change. The goals of the intervention are to offset negative climate impacts on maize yields and capitalize on the profitability of milk production. Similar to Core Question 3, this analysis is undertaken for future RAPs and their associated climate scenarios.

In both RAPs, there are future scenarios where average maize net returns are predicted to decrease as a result of climate change across Kenya. These negative economic impacts are the result of decreases in maize yields caused by climate change. As such, the technological intervention aims to increase maize yields in future climate scenarios by increasing fertilizer application on each farm. In terms of milk production, the Core Question 2 analysis indicates that adding improved breed cows may substantially increase milk net returns in current production systems. To implement a similar intervention in future production systems, each farm is provided with multiple improved breed cows. With the increase in herd size, farms also apply more manure with the intervention. The only difference between the interventions in RAP 4 and RAP 5 is related to soil improvement. In RAP 5, soil quality is lower than in the current period and, as a result, the intervention includes soil improvement practices that restore soil to its current (2007) quality.

\section{Integrated Assessment Results}

\section{Core Question 1}

\section{Crop simulation results}

Table 5 shows how the average simulated yields for the current period compare to the observed yields in 2007, based on the DSSAT model. The CM0 (baseline) 
Table 5. Current period simulated yield results, DSSAT.

\begin{tabular}{|c|c|c|c|c|c|c|c|}
\hline \multirow[b]{2}{*}{ Strata } & \multirow[b]{2}{*}{$\begin{array}{l}\text { Observed } \\
\text { Yield }\end{array}$} & \multicolumn{3}{|c|}{ CM0 } & \multicolumn{3}{|c|}{ CM1 } \\
\hline & & $\begin{array}{l}\text { Simulated } \\
\text { Yield }\end{array}$ & Correlation & $\begin{array}{c}\text { R- } \\
\text { squared }\end{array}$ & $\begin{array}{l}\text { Simulated } \\
\text { Yield }\end{array}$ & Correlation & $\begin{array}{c}\text { R- } \\
\text { squared }\end{array}$ \\
\hline Low & 1287 & 859 & 0.74 & 0.55 & 842 & 0.69 & 0.48 \\
\hline Low-milk & 1340 & 943 & 0.68 & 0.47 & 918 & 0.74 & 0.54 \\
\hline Medium & 2373 & 2014 & 0.77 & 0.60 & 1889 & 0.76 & 0.58 \\
\hline Medium-milk & 2729 & 2162 & 0.65 & 0.42 & 2072 & 0.68 & 0.47 \\
\hline High & 2740 & 2358 & 0.68 & 0.46 & 2246 & 0.64 & 0.41 \\
\hline High-milk & 3136 & 2911 & 0.75 & 0.56 & 2788 & 0.73 & 0.53 \\
\hline
\end{tabular}

Note: All yield values are shown in $\mathrm{kg} / \mathrm{ha}$.

yields are simulated for 2007 only and the CM1 (current climate) yields are the average simulated yields from 1980-2009. The crop model's average predictions are highest in the high MPZ and lowest in the low MPZ, similar to the observed yields. The average predictions are consistently lower than the observed values. The ratio of CM1/CM0 remains close to 1 , showing that the 30 -year simulation does a reasonably good job of predicting the 2007 result for all MPZs, despite the offset from observed values. Table 5 also shows the correlation between these simulated yields and the observed yields, as well as the R-squared values resulting from a regression of the simulated yields on the observed yields. The correlation coefficients are around 0.70 and are similar across the strata. The R-squared values are likewise similar across the strata and these values are around 0.50 .

Table 6 shows statistics on the DSSAT relative yields for each MPZ under the RCP 4.5 scenario. The relative yield is the ratio of the maize yield under the future climate (CM2) compared to the maize yield under the current climate (CM1), for a given farm. Both the CM1 and CM2 yields are 30-year averages from the crop model simulations. A relative yield of 1 indicates no climate impact on yield and a value below (above) 1 indicates a negative (positive) climate impact. In both CM1 and $\mathrm{CM} 2$, the simulations are performed under current farm management (e.g., hybrid use, fertilizer use).

The relative yields in Table 6 indicate a negative average impact on yields in the low MPZ. The lowest average relative yield is 0.89 occurring in the middle GCM and the highest relative yield is 0.98 in the cool/wet GCM. The average relative yields are also less than 1 for all GCMs in the medium MPZs. The average relative yields vary between 0.84 in the hot/wet GCM and 0.95 in the cool/dry GCM. The high MPZ is the only MPZ with an average relative yield above 1 for any of the GCMs. The cool/wet GCM leads to an average relative yield of 1.01 in this MPZ, 
Table 6. DSSAT relative yields by Maize Potential Zones (MPZs), RCP 4.5.

\begin{tabular}{|c|c|c|c|c|c|c|}
\hline \multirow{2}{*}{$\begin{array}{l}\text { GCM } \\
\text { Characterization }\end{array}$} & \multicolumn{2}{|c|}{ Low Potential } & \multicolumn{2}{|c|}{ Medium Potential } & \multicolumn{2}{|c|}{ High Potential } \\
\hline & Mean & CV (\%) & Mean & CV (\%) & Mean & CV (\%) \\
\hline Cool/wet & 0.98 & 9.4 & 0.91 & 5.9 & 1.01 & 9.7 \\
\hline Cool/dry & 0.95 & 5.7 & 0.95 & 4.2 & 0.96 & 8.6 \\
\hline Middle & 0.89 & 6.5 & 0.93 & 11.2 & 0.85 & 20.4 \\
\hline Hot/wet & 0.90 & 16.2 & 0.84 & 13.2 & 0.95 & 15.5 \\
\hline Hot/dry & 0.89 & 8.6 & 0.89 & 7.7 & 0.86 & 17.9 \\
\hline
\end{tabular}

Table 7. DSSAT relative yields by Maize Potential Zones (MPZs), RCP 8.5.

\begin{tabular}{|c|c|c|c|c|c|c|}
\hline \multirow{2}{*}{$\begin{array}{l}\text { GCM } \\
\text { Characterization }\end{array}$} & \multicolumn{2}{|c|}{ Low Potential } & \multicolumn{2}{|c|}{ Medium Potential } & \multicolumn{2}{|c|}{ High Potential } \\
\hline & Mean & CV (\%) & Mean & $\mathrm{CV}(\%)$ & Mean & CV $(\%)$ \\
\hline Cool/wet & 0.94 & 11.3 & 0.88 & 7.8 & 0.97 & 12.1 \\
\hline Cool/dry & 0.92 & 8.2 & 0.93 & 6.2 & 0.96 & 10.0 \\
\hline Middle & 0.91 & 8.5 & 0.89 & 7.9 & 0.87 & 17.0 \\
\hline Hot/wet & 0.89 & 15.6 & 0.79 & 11.2 & 0.90 & 17.4 \\
\hline Hot/dry & 0.86 & 8.3 & 0.84 & 12.6 & 0.76 & 24.3 \\
\hline
\end{tabular}

meanwhile, the lowest relative yield is 0.85 and occurs in the middle GCM, with the hot/dry GCM also exhibiting low relative yield (0.86).

Table 7 shows the DSSAT relative yields for each GCM under the RCP 8.5 scenario. In general, the DSSAT crop model predicts a negative climate impact across the various GCMs and MPZs. In the low MPZ, the average relative yields range from 0.86 to 0.94 across the five GCMs. The highest average value occurs in the cool/wet GCM and the lowest average value occurs in the hot/dry GCM. The average relative yields vary between 0.79 and 0.93 across the five GCMs in the medium MPZ. The highest value occurs in the cool/dry GCM and the lowest value occurs in the hot/wet GCM. Meanwhile, in the high MPZ, the highest average relative yield is 0.97 and the lowest average relative yield in 0.76 . Similar to the low MPZ, the cool/wet (hot/dry) GCM produces the highest (lowest) average relative yield.

\section{Economic analysis}

The economic analysis for Core Question 1 assesses the potential impacts of climate on current agricultural systems. The crop model results given in Tables 6 and 7 are used to quantify the impact of climate on maize production. However, other crop activities and livestock activities are not modeled under the future climate. As such, 
to gain an understanding of the economic impacts of climate change on the household as a whole, a sensitivity analysis is used. In one case, all farm activities are assumed to be impacted by the same magnitude as maize; in other words, the maize relative yield is applied to all farm activities. This represents a case where the whole farm is impacted by climate. The second case is simulated with the assumption that only maize is impacted by climate change; for all other activities, a relative yield of 1 is applied for all farms. This assumption examines the importance of maize, and its climate sensitivity, in total farm production and income.

For detailed results of the economic analysis, we refer to Claessens et al. (2017). The economic results across the various GCMs and RCPs predict that the current maize-based systems in Kenya will be negatively impacted by climate change. The majority of households are vulnerable (i.e., have lower income with climate change) in each simulation. The economic simulations predict the percentage of vulnerable households to be between 50\% and 70\% across the GCMs, RCPs, and relative yield assumptions. Moreover, per capita income is predicted to decrease, while poverty is predicted to increase. The results differ somewhat between RCP 4.5 and RCP 8.5. The relative yields are generally higher in RCP 4.5 than RCP 8.5, but they are lower in the hotter GCMs.

These relative yield characteristics carry over into the economic results. The climate change impacts are generally more negative in RCP 8.5 than in RCP 4.5: more vulnerable households, lower per capita incomes, and higher poverty rates. Moreover, the strata-level results indicate that the farms in the high MPZs are potentially the most vulnerable to climate impact in Kenya. In the worst case, maize yields in this area are predicted to decrease by a larger degree than in the low and medium MPZs. Moreover, farms in the high MPZs are more reliant on maize than the other MPZs, where household income is relatively diversified across off-farm work, maize, other crops, and livestock.

\section{Core Question 2}

\section{Technology intervention for maize-based systems in Kenya}

The technological intervention tested in this study is designed to increase maize yields across all the MPZs in Kenya and is described in section "RAP 4: Safi KenyaThe Greener Kenya". The specific components of this intervention are summarized in Table 8. This table describes how various modeling parameters (both crop and economic) are changed for each farm under the technological intervention, compared to the current farming systems.

Insights from the CTWN analysis and expert opinions suggest that current levels of fertilizer - even in the high MPZs - are relatively low and have much room to improve. The current application rates of $\mathrm{Nkg} / \mathrm{ha}$, the proportion of farmers using 
Table 8. Technological intervention components.

\begin{tabular}{ll}
\hline Parameters & \multicolumn{1}{c}{ Description of Change } \\
\hline Fertilizer application & $\begin{array}{c}\text { Increase by } 25 \mathrm{~N}(\mathrm{~kg} / \mathrm{ha}) \text { for the medium and } \\
\text { high MPZs. Increase by } 10 \mathrm{~N}(\mathrm{~kg} / \mathrm{ha}) \text { for the } \\
\text { low MPZs. Only applies for farms currently } \\
\text { using fertilizer. }\end{array}$ \\
$\begin{array}{l}\text { Manure application } \\
\text { Increase by 1000 kg/ha for all farms. } \\
\text { Herd size }\end{array}$ & $\begin{array}{l}\text { Decrease by 25\%. } \\
\text { Increase by one improved breed cow for all } \\
\text { farms. This is parameterized using improved } \\
\text { breed statistics in the data. }\end{array}$ \\
Milk yield & $\begin{array}{c}\text { Increase by } 1.5 \text { in the low MPZs and 1.36 in } \\
\text { the medium and high MPZs. }\end{array}$ \\
Milk production & $\begin{array}{c}\text { Increase according to change in herd and } \\
\text { feeding strategy (relative yield method). } \\
\text { Increase according to change in herd and } \\
\text { feeding strategy (relative yield method). }\end{array}$ \\
\hline Milk production cost &
\end{tabular}

Table 9. Fertilizer statistics for Core Question 2.

\begin{tabular}{lccc}
\hline Strata & $\begin{array}{c}\text { Proportion } \\
\text { Using } \\
\text { Fertilizer }\end{array}$ & $\begin{array}{c}\text { Observed N } \\
\text { Application } \\
\text { (kg/ha)* }\end{array}$ & $\begin{array}{c}\text { CQ2 N } \\
\text { Application } \\
\text { (kg/ha) }\end{array}$ \\
\hline Low & 0.22 & 7.2 & 17.2 \\
Low-milk & 0.45 & 8.8 & 18.8 \\
Medium & 0.79 & 24.3 & 49.3 \\
Medium-milk & 0.79 & 28.9 & 53.9 \\
High & 0.78 & 33.3 & 58.3 \\
High-milk & 0.88 & 33.4 & 58.4 \\
\hline
\end{tabular}

Note: *Average rate for those who use fertilizer. Does not include full sample.

fertilizer, and the fertilizer quantity that is simulated in the Core Question 2 economic analysis are shown in Table 9. Note that these statistics correspond to farmers with positive rates of fertilizer application.

Table 10 shows a comparison of milk statistics for each stratum and for farms that only own the improved breed cows. The resolution of the data only allows for identification of farm-level management and productivity; costs and productivity cannot be distinguished by breed type for farms that own multiple breeds. As such, the improved breed statistics are only distinguished by examining the farms that exclusively own improved breeds. Moreover, these farms are a sub-sample of the total sample of milk- selling farms. Table 10 shows the yearly averages of milk yield, milk sold, purchased feed cost per cattle, total cost per cattle, milk revenue per cow, and milk price. Total cost comprises the purchased feed, veterinary, tick 
Table 10. Milk statistics by MPZ and breed type.

\begin{tabular}{lccccccc}
\hline & & $\begin{array}{c}\text { Milk } \\
\text { Produced } \\
\text { Strata }\end{array}$ & $\begin{array}{c}\text { Milk Sold } \\
\text { per Cow } \\
\text { (lt) }\end{array}$ & $\begin{array}{c}\text { Feed } \\
\text { Cost per } \\
\text { Animal } \\
\text { (KSh) }\end{array}$ & $\begin{array}{c}\text { Total } \\
\text { Cost per } \\
\text { Animal } \\
(\text { KSh) }\end{array}$ & $\begin{array}{c}\text { Milk } \\
\text { Revenue } \\
\text { per Cow } \\
(\text { KSh) }\end{array}$ & $\begin{array}{c}\text { Milk } \\
\text { Price } \\
(\text { KSh/lt) }\end{array}$ \\
\hline Low-milk & 73 & 819 & 519 & 289 & 710 & 14,892 & 27.4 \\
Medium-milk & 259 & 1564 & 976 & 2163 & 3153 & 16,653 & 18.4 \\
High-milk & 170 & 1705 & 971 & 832 & 1732 & 15,257 & 16.1 \\
Improved breed & 60 & 2352 & 1584 & 3860 & 5336 & 25,273 & 16.1 \\
\hline
\end{tabular}

and worm, and insemination costs. The improved breeds have higher yields and higher amounts of milk sold, on average. Moreover, the farms using these breeds tend to have higher feed and total costs than other farms. Looking at milk revenue per cow, the improved breeds are associated with revenue that more than accounts for higher costs, compared to the averages in each MPZ.

Milk yield and cost data, along with farm-level milk price, are used to estimate how an improved breed cow impacts milk net returns. The technological intervention assumes that the improved breed is more productive than local and cross breeds due to its inherent productivity and improved management. These observed statistics capture both of these attributes: the improved breed has higher yields and is given more purchased feed (as well as other services). As such, the yield and cost statistics from the improved breed farms are assumed to be reasonable approximations of how an additional improved breed cow would impact average milk net returns.

The intervention also implies that pre-existing herds are managed using improved feeding strategies. These strategies will impact milk yield for this portion of the herd. Results from Shikuku et al. (2017) are used to approximate the relative yield of improved feeding across all the MPZs in Kenya. These authors simulate the impact of improved feeding strategies for local breeds in Tanzania using the Ruminant Model (Herrero et al., 2002). The simulations predict a relative yield of 1.50 from improved feeding during the dry season. This value is used to represent yield changes in the low MPZs, which are generally drier areas of Kenya. For the wet season, Shikuku et al. (2017) estimate a relative yield of 1.36, which is assumed for the wetter areas of Kenya in this analysis, the high and medium MPZs. These areas already use more purchased feed than the low MPZs and, as such, are expected to have less milk yield improvement from the intervention.

\section{Crop simulation results}

The DSSAT crop model is used to predict maize yield changes corresponding to the technological intervention of increased fertilizer and manure application. Table 11 shows the simulated relative yield statistics for each stratum. The farm-level yields 
Table 11. Maize relative yield statistics, Core Question 2.

\begin{tabular}{lcc}
\hline Strata & Average & CV \\
\hline Low & 2.26 & 32.7 \\
Low-milk & 1.80 & 35.3 \\
Medium & 2.10 & 39.9 \\
Medium-milk & 1.89 & 39.6 \\
High & 1.86 & 42.2 \\
High-milk & 1.66 & 34.7 \\
\hline
\end{tabular}

are simulated for each year in the historical period (1980-2010) under the observed management (CM1 crop simulation) and under management representing the intervention (CM3 crop simulation). Table 11 implies that, on average, the intervention leads to yield increases of $66 \%$ to $126 \%$ across the strata. The highest average relative yield is in the low MPZ for farms without milk and the lowest average relative yield is in the high MPZ for farms with milk. These relative yield values suggest that maize farmers can nearly double the current yields by increasing $\mathrm{N}$ and manure application, which also reflects that the current application rates are low. Within each MPZ, the relative yields tend to be higher for farms without milk. These farms may have higher maize yield benefits from the intervention because they have a lower degree of crop-livestock integration (e.g., manure use) in the current system.

\section{Economic analysis}

The system 1 parameters for this analysis are the same as those from Core Question 1. In other words, system 1 represents the observed maize-based system in Kenya. System 2 represents the system with the technological intervention. The economic differences between the two systems are the maize and milk net returns. Maize net returns for system 2 are calculated based on simulated yield changes that result from the technological intervention. However, there are specific cost considerations in this case. First, manure cost is assumed to be the same between systems because the additional manure in system 2 is produced on farm. Second, the system 2 fertilizer cost is calculated based on a $25 \%$ reduction in fertilizer price and the fertilizer application rate under the intervention. Third, all other maize costs (seed and land preparation) for system 2 are calculated using the relative yield method.

The milk net returns for each farm under the technological intervention are calculated as the net returns to the additional cow plus the net returns to the pre-existing cows with improved feeding. The additional cow net returns are approximated for each farm using the mean milk sold and the mean cost of the improved breeds from Table 10. 
Table 12. DSSAT relative yields by Maize Potential Zone (MPZ), RAP 4 (RCP 4.5).

\begin{tabular}{|c|c|c|c|c|c|c|c|}
\hline & & \multicolumn{2}{|c|}{ Low Potential } & \multicolumn{2}{|c|}{ Medium Potential } & \multicolumn{2}{|c|}{ High Potential } \\
\hline & & Mean & $\mathrm{CV}(\%)$ & Mean & CV $(\%)$ & Mean & $\mathrm{CV}(\%)$ \\
\hline \multirow[t]{5}{*}{ GCM characterization } & Cool/wet & 1.06 & 11.9 & 0.96 & 4.4 & 1.05 & 12.2 \\
\hline & Cool/dry & 1.00 & 4.5 & 0.97 & 3.1 & 0.96 & 5.7 \\
\hline & Middle & 1.02 & 1.8 & 1.02 & 1.1 & 1.02 & 1.3 \\
\hline & Hot/wet & 1.02 & 16.6 & 0.94 & 7.0 & 1.01 & 15.9 \\
\hline & Hot/dry & 0.95 & 8.4 & 0.92 & 6.8 & 0.83 & 17.9 \\
\hline
\end{tabular}

For detailed results of the economic analysis, we refer to Claessens et al. (2017). The economic simulation suggests that the intervention is beneficial for a large majority of farms in each of the MPZs of Kenya. In particular, maize productivity increases due to increased fertilizer and manure application and milk productivity increases due to improved feeding and the addition of an improved breed cow. Both of these productivity gains come with increased input costs. Nonetheless, the revenue that results from yield improvements tends to outweigh the excess costs and leads to increases in both maize and milk net returns. By improving farm net returns, the intervention is expected to increase the per capita income and decrease the poverty rate.

\section{Core Question 3}

In order to model the farming system under future conditions, elements from the RAP narratives are used to specify changes in the modeling inputs for both crop and economic models. The RAPs specify a number of management changes to characterize future maize production in Kenya. Table 13 shows how the current maize systems are modified for RAP 4 and RAP 5.

All of the management changes in Table 13 are relative to the current period management. Both RAP narratives indicate that farmers increase fertilizer and manure application rates. This change is represented by farmers in the high and medium MPZs increasing fertilizer by $30 \mathrm{~N} \mathrm{~kg} / \mathrm{ha}$ and farmers in the low MPZs increasing fertilizer by $15 \mathrm{~N} \mathrm{~kg} / \mathrm{ha}$. These application rates are the same for both RAPs. However, manure application differs by RAP; in RAP 4, all farms in the milk strata increase manure application by $1000 \mathrm{~kg} / \mathrm{ha}$, whereas in RAP 5, the milk farms increase manure application by $500 \mathrm{~kg} / \mathrm{ha}$. The application rate is lower in RAP 5 because this RAP is associated with less organic fertilizer use and less croplivestock integration than in RAP 4.

Another component of both RAPs is the increased use of improved maize varieties, which is modeled by modifying the genetic coefficients to achieve a $10 \%$ 
Table 13. RAP 4 and RAP 5 crop modeling components.

\begin{tabular}{|c|c|c|c|}
\hline & & RAP 4 & RAP 5 \\
\hline \multirow[t]{4}{*}{$\begin{array}{l}\text { High and Medium } \\
\text { Potential Zones }\end{array}$} & Fertilizer & $\begin{array}{l}\text { Increase by } 30 \mathrm{~N} \mathrm{~kg} / \mathrm{ha} \text { on all } \\
\text { farms }\end{array}$ & $\begin{array}{l}\text { Increase by } 30 \mathrm{Nkg} / \mathrm{ha} \text { on all } \\
\text { farms }\end{array}$ \\
\hline & Genetic & $10 \%$ improvement & $10 \%$ improvement \\
\hline & Manure & $\begin{array}{l}\text { Increase by } 1000 \mathrm{~kg} / \mathrm{ha} \text { for milk } \\
\text { strata }\end{array}$ & $\begin{array}{l}\text { Increase by } 500 \mathrm{~kg} / \mathrm{ha} \text { for milk } \\
\text { strata }\end{array}$ \\
\hline & Soil & No change & $\begin{array}{l}\text { Degraded to achieve } 15 \% \\
\text { lower yield than RAP } 4 *\end{array}$ \\
\hline \multirow[t]{4}{*}{$\begin{array}{l}\text { Low Potential } \\
\text { Zones }\end{array}$} & Fertilizer & $\begin{array}{l}\text { Increase by } 15 \mathrm{Nkg} / \mathrm{ha} \text { on all } \\
\text { farms }\end{array}$ & $\begin{array}{l}\text { Increase by } 15 \mathrm{Nkg} / \mathrm{ha} \text { on all } \\
\text { farms }\end{array}$ \\
\hline & Genetic & $10 \%$ improvement & $10 \%$ improvement \\
\hline & Manure & $\begin{array}{l}\text { Increase by } 1000 \mathrm{~kg} / \mathrm{ha} \text { for milk } \\
\text { strata }\end{array}$ & $\begin{array}{l}\text { Increase by } 500 \mathrm{~kg} / \mathrm{ha} \text { for milk } \\
\text { strata }\end{array}$ \\
\hline & Soil & No change & $\begin{array}{l}\text { Degraded to achieve } 15 \% \\
\text { lower yield than RAP } 4 *\end{array}$ \\
\hline
\end{tabular}

Note: *Based on difference in IFPRI IMPACT Yield Trends. Rainfed maize trend for RAP $4=1.70$ and rainfed maize trend for RAP $5=1.44$.

increase in yields. Last, the crop modeling for RAP 5 also incorporates degradation of the current soils. Soil degradation is consistent with the RAP 5 narrative and it may explain why the global economic model (described in detail below) predicts lower maize yields in RAP 5 than RAP 4. The DSSAT model is used to simulate maize yields under management representative of the descriptions in Table 13

Table 14 shows how future changes in crop and milk production are quantified under each RAP. Similar to Table 13, these changes are relative to the observed maize-based systems: the trend values represent the ratio of the future value to the current value for each parameter. The trend values are used in the economic analysis to characterize future maize-based systems under each RAP. In Table 14, the "Description" columns provide background information on the source of the trend values. Some of these changes were developed as plausible changes based on the SSPs and other studies during RAP meetings, while other changes are based on trends from the International Food Policy Research Institute's (IFPRI) International Model for Policy Analysis of Agricultural Commodities and Trade (IMPACT) model (Robinson et al., 2015).

The IMPACT model is a global model that predicts future prices, yields, areas, and total production for a number of commodities at the global level. The model also incorporates various future scenarios (SSPs, RCPs, etc). The trends (i.e., the ratio of 
Table 14. Quantification of parameter changes under each RAP.

\begin{tabular}{|c|c|c|c|c|}
\hline & \multicolumn{2}{|r|}{ RAP 4} & \multicolumn{2}{|r|}{ RAP 5} \\
\hline & Trend & Description & Trend & Description \\
\hline Household size & 0.8 & $\begin{array}{l}\text { From discussions at RAP } \\
\text { meeting. }\end{array}$ & 1.2 & $\begin{array}{l}\text { From discussions at RAP } \\
\text { meeting. }\end{array}$ \\
\hline Off-farm income & 1.5 & $\begin{array}{l}\text { From discussions at RAP } \\
\text { meeting. }\end{array}$ & 1.8 & $\begin{array}{l}\text { From discussions at RAP } \\
\text { meeting. }\end{array}$ \\
\hline \multicolumn{5}{|l|}{ Crop production } \\
\hline Farm size & 1.4 & $\begin{array}{l}\text { From discussions at RAP } \\
\text { meeting. } \mathrm{CV} \text { increases } \\
\text { by } 10 \% \text { also. }\end{array}$ & 1 & $\begin{array}{l}\text { From discussions at RAP } \\
\text { meeting. CV increases } \\
\text { by } 20 \% \text { also. }\end{array}$ \\
\hline Maize area & $1.4,0.84$ & $\begin{array}{l}\text { Increases in proportion to } \\
\text { farm size. Low-milk } \\
\text { strata allocate } 40 \% \text { of } \\
\text { future area to Napier } \\
\text { grass leading to a } 0.84 \\
\text { trend for maize area. }\end{array}$ & $0.8-1.1$ & $\begin{array}{l}\text { Low-milk strata allocate } \\
20 \% \text { of area to Napier } \\
\text { grass leading to a } 0.80 \\
\text { trend for maize area. } \\
\text { Other low potential } \\
\text { farms do not change } \\
\text { allocation (trend }=1 \text { ). } \\
\text { The high and medium } \\
\text { potential zones increase } \\
\text { maize area by } 10 \% \text {. }\end{array}$ \\
\hline Maize yield & 1.7 & IFPRI IMPACT trend. & 1.44 & IFPRI IMPACT \\
\hline $\begin{array}{l}\text { Maize price (no } \\
\text { CC) }\end{array}$ & 1.51 & IFPRI IMPACT trend. & 1.37 & IFPRI IMPACT \\
\hline $\begin{array}{l}\text { Maize price (with } \\
\text { CC) }\end{array}$ & 1.6 & IFPRI IMPACT trend. & 1.57 & IFPRI IMPACT \\
\hline Maize cost & 1.51 & $\begin{array}{l}\text { Assumed same as maize } \\
\text { price. }\end{array}$ & 1.37 & $\begin{array}{l}\text { Assumed same as maize } \\
\text { price. }\end{array}$ \\
\hline Other crops area & $1.4,0.84$ & $\begin{array}{l}\text { Increases in proportion to } \\
\text { farm size. Low-milk } \\
\text { strata allocate } 40 \% \text { of } \\
\text { future area to Napier } \\
\text { grass leading to a } 0.84 \\
\text { trend for maize area. }\end{array}$ & $0.8-1$ & $\begin{array}{l}\text { Changes in accordance to } \\
\text { the maize area change } \\
\text { for each stratum. }\end{array}$ \\
\hline Other crops yield & 2.16 & $\begin{array}{l}\text { IFPRI IMPACT aggregate } \\
\text { trend.* }\end{array}$ & 1.95 & $\begin{array}{l}\text { IFPRI IMPACT aggregate } \\
\text { trend.* }\end{array}$ \\
\hline $\begin{array}{l}\text { Other crops price } \\
\text { (no CC) }\end{array}$ & 1.18 & $\begin{array}{l}\text { IFPRI IMPACT aggregate } \\
\text { trend.* }\end{array}$ & 1.35 & $\begin{array}{l}\text { IFPRI IMPACT aggregate } \\
\text { trend.* }\end{array}$ \\
\hline $\begin{array}{l}\text { Other crops price } \\
\text { (with CC) }\end{array}$ & 1.41 & $\begin{array}{l}\text { IFPRI IMPACT aggregate } \\
\text { trend.* }\end{array}$ & 1.73 & $\begin{array}{l}\text { IFPRI IMPACT aggregate } \\
\text { trend.* }\end{array}$ \\
\hline Other crops cost & 1.18 & $\begin{array}{l}\text { Assumed same as other } \\
\text { crops price. }\end{array}$ & 1.35 & $\begin{array}{l}\text { Assumed same as other } \\
\text { crops price. }\end{array}$ \\
\hline
\end{tabular}


Table 14. (Continued)

\begin{tabular}{|c|c|c|c|c|}
\hline & \multicolumn{2}{|r|}{ RAP 4} & \multicolumn{2}{|r|}{ RAP 5} \\
\hline & Trend & Description & Trend & Description \\
\hline \multicolumn{5}{|l|}{$\begin{array}{l}\text { Milk } \\
\quad \text { production }\end{array}$} \\
\hline Herd size & 1.35 & $\begin{array}{l}\text { From discussions at RAP } \\
\text { meeting. CV increases } \\
\text { by } 25 \% \text { also. }\end{array}$ & 1 & $\begin{array}{l}\text { From discussions at RAP } \\
\text { meeting. } \mathrm{CV} \text { increases } \\
\text { by } 35 \% \text { also. }\end{array}$ \\
\hline Milk yield & $1.36,1.5$ & $\begin{array}{l}\text { Approximate relative } \\
\text { yields from improved } \\
\text { feeding in Shikuku et al. } \\
\text { (2017). The lower value } \\
\text { corresponds to the high } \\
\text { and medium zones; the } \\
\text { higher value } \\
\text { corresponds to the low } \\
\text { zones. }\end{array}$ & $1.36,1.5$ & $\begin{array}{l}\text { Approximate relative } \\
\text { yields from improved } \\
\text { feeding in Shikuku et al. } \\
\text { (2017). The lower value } \\
\text { corresponds to the high } \\
\text { and medium zones; the } \\
\text { higher value } \\
\text { corresponds to the low } \\
\text { zones. }\end{array}$ \\
\hline $\begin{array}{l}\text { Milk price } \\
\text { (no } \mathrm{CC})\end{array}$ & 1.21 & IFPRI IMPACT trend. & 1.12 & IFPRI IMPACT \\
\hline $\begin{array}{l}\text { Milk price } \\
\text { (with CC) }\end{array}$ & 1.23 & IFPRI IMPACT trend. & 1.14 & IFPRI IMPACT \\
\hline Milk cost & $1.65,1.82$ & $\begin{array}{l}\text { Changes with milk yield } \\
\text { and milk price. }\end{array}$ & $1.52,1.68$ & $\begin{array}{l}\text { Changes with milk yield } \\
\text { and milk price. }\end{array}$ \\
\hline
\end{tabular}

Note: $\mathrm{CV}=$ coefficient of variation.

* see Table 5.4.3 for aggregate trend calculations.

the 2050 value to the baseline value in 2005) presented in Table 15 are IMPACT's predictions for Kenya for the scenarios that correspond to each RAP (Wiebe et al., 2015).

In the RAP 4 narrative, household sizes decrease and off-farm income increases. These are quantified as a $20 \%$ decrease in household size and a $50 \%$ increase in off-farm income. In RAP 5, household sizes increase and off-farm income increases, but to a larger extent than in RAP 4 because overall economic growth is higher in RAP 5. This analysis calculates the RAP 5 household size as $20 \%$ higher than the current household size, while off-farm income is $80 \%$ higher in RAP 5 than in the current period.

Farm sizes increase by $40 \%$ in RAP 4 but do not change in RAP 5. In both pathways, the relative variation (i.e., coefficient of variation $(\mathrm{CV})$ ) increases to represent increased consolidation of farm land. In RAP 4, maize area in the high and medium MPZs increases in proportion to farm size (40\%); while in RAP 5, maize area increases by $10 \%$ in these same locations and represents increased reliance on maize since average farm size does not change. In the low MPZs, the farms without 
Table 15. Range of economic results - RAP 5, RCP 8.5, maize impact on all activities.

\begin{tabular}{|c|c|c|c|c|c|c|c|c|c|c|c|c|}
\hline \multirow[b]{2}{*}{ Strata } & \multicolumn{6}{|c|}{ Least Vulnerable } & \multicolumn{6}{|c|}{ Most Vulnerable } \\
\hline & GCM & Price & $\begin{array}{c}\text { Vulnera } \\
(\%)\end{array}$ & $\begin{array}{c}\text { Net } \\
\text { Impact } \\
(\%)\end{array}$ & $\begin{array}{c}\text { Change } \\
\text { in PCI } \\
(\%)\end{array}$ & $\begin{array}{c}\text { Change } \\
\text { in } \\
\text { Poverty } \\
\text { Rate }(\%)\end{array}$ & GCM & Price & $\begin{array}{c}\text { Vulneral } \\
(\%)\end{array}$ & $\begin{array}{c}\text { Net } \\
\text { le Impact } \\
(\%)\end{array}$ & $\begin{array}{c}\text { Change } \\
\text { in PCI } \\
(\%)\end{array}$ & $\begin{array}{c}\text { Change } \\
\text { in } \\
\text { Poverty } \\
\text { Rate }(\%)\end{array}$ \\
\hline Low & Cool/dry & High & 36.7 & 12.9 & 5.7 & -2.4 & Hot/dry & Low & 44.3 & 5.0 & 1.7 & -0.8 \\
\hline Low-milk & Cool/dry & High & 31.8 & 15.4 & 8.3 & -2.7 & Hot/dry & Low & 42.9 & 5.0 & 2.2 & -0.9 \\
\hline Medium & Cool/dry & High & 34.1 & 17.8 & 14.5 & -4.7 & Hot/dry & Low & 44.8 & 4.9 & 3.5 & -1.4 \\
\hline Medium-milk & Cool/dry & High & 33.5 & 16.4 & 14.2 & -2.1 & Hot/dry & Low & 46.7 & 2.7 & 2.1 & -0.4 \\
\hline High & Cool/dry & High & 37.5 & 13.6 & 8.5 & -3.9 & Hot/dry & Low & 62.8 & -11.7 & -5.8 & 2.6 \\
\hline High-milk & Cool/dry & High & 32.6 & 12.2 & 9.1 & -2.8 & Hot/dry & Low & 65.7 & -9.5 & -6.0 & 2.8 \\
\hline Aggregate & Cool/dry & High & 34.0 & 15.2 & 11.3 & -2.9 & Hot/dry & Low & 51.2 & 0.0 & 0.3 & 0.2 \\
\hline
\end{tabular}


milk increase maize area in proportion to farm size in RAP 4 and do not change maize area in RAP 5. The farms with milk in the low MPZs allocate $40 \%$ of future farm area to Napier grass in RAP 4, which leads to a $16 \%$ reduction in maize area. In RAP 5, these farms allocate $20 \%$ of farm area to Napier, reducing maize area by $20 \%$. Maize yields are expected to increase in both RAPs due to management and variety improvements.

The IMPACT model predicts that the maize yields will be $70 \%$ higher in RAP 4 and $44 \%$ higher in RAP 5 than current yields. Both of these are yield trends without climate change. Moreover, the maize price is expected to increase in each RAP. Without climate change, the IMPACT model predicts the maize price trend as 1.51 in RAP 4 and 1.37 in RAP 5. Both these trends are higher in the IMPACT model with climate change: 1.60 in RAP 4 and 1.57 in RAP 5. Additionally, the maize management changes and the changes in future input prices are assumed to increase the cost of maize production. The trend of maize production cost is assumed to be the same as the trend of maize price for each RAP.

The RIA analysis of Kenyan maize-based systems aggregates all non-maize crops into a single category referred to as other crops. For RAP 4, the area allocated to these crops changes by the same amount as maize area. In other words, the proportion of maize area to other crops area is kept constant between current and future time periods. However, for RAP 5, this area changes in accordance with the maize area changes discussed above; in particular, the proportion of maize area to other crops area increases in the future time period for RAP 5.

The yield, price, and cost trends for the other crops activity are approximated using the IMPACT trends of the most common crops grown in the survey data. These crops are bananas, beans, cowpeas, potatoes, avocados, mangos, sweet potatoes, onions, and Sukuma wiki. Table 16 shows the IMPACT trends for commodities that correspond to these crops in Kenya. The aggregate trends used in Core Question 3 are the average trend values for these commodities. (The row labelled "Average" in Table 16 shows the trend values from Table 14 for the other crops activities.)

In RAP 4, these commodities have yield trends between 1.48 and 3.43, price trends between 1.06 and 1.42 without climate change, and price trends between 1.18 and 1.75 with climate change. When these trends are aggregated using their averages, the other crops activity is parameterized with a 2.16 yield trend, 1.18 price trend without climate change, and 1.41 price change with climate change in RAP 4.

The RAP 5 trends differ somewhat, as prices are higher and yields lower than those in RAP 4. The yield trend across the commodities ranges from 1.27 to 3.22 with an aggregate trend of 1.95 , the price trend without climate change ranges from 1.18 to 1.85 with an aggregate trend of 1.35 , and the price trend with climate change 
Table 16. IMPACT trends for common crops in Kenyan maize-based systems.

\begin{tabular}{|c|c|c|c|c|c|c|c|}
\hline \multirow[b]{2}{*}{$\begin{array}{l}\text { IMPACT } \\
\text { Commodity }\end{array}$} & \multicolumn{3}{|c|}{ RAP 4} & \multicolumn{3}{|c|}{ RAP 5} & \multirow[b]{2}{*}{ Examples } \\
\hline & $\begin{array}{c}\text { Price } \\
(\text { No } C C)\end{array}$ & $\begin{array}{c}\text { Price } \\
\text { (With CC) }\end{array}$ & Yield & $\begin{array}{c}\text { Price } \\
\text { (No CC) }\end{array}$ & $\begin{array}{c}\text { Price } \\
\text { (With CC) }\end{array}$ & Yield & \\
\hline Banana & 1.15 & 1.48 & 2.13 & 1.27 & 1.78 & 1.88 & \\
\hline Bean & 1.06 & 1.18 & 2.38 & 1.22 & 1.41 & 2.15 & \\
\hline Cowpea & 1.42 & 1.75 & 3.43 & 1.85 & 2.36 & 3.22 & \\
\hline Potato & 1.19 & 1.37 & 1.48 & 1.18 & 1.47 & 1.27 & \\
\hline Sub-tropical fruit & 1.27 & 1.57 & 2.36 & 1.37 & 1.82 & 2.07 & Avocados, mangos \\
\hline Sweet potato & 1.07 & 1.29 & 1.72 & 1.38 & 1.83 & 1.60 & \\
\hline Vegetable & 1.10 & 1.27 & 1.59 & 1.19 & 1.47 & 1.43 & Onions, sukuma wiki \\
\hline Average & 1.18 & 1.41 & 2.16 & 1.35 & 1.73 & 1.95 & \\
\hline
\end{tabular}

Note: Yield trends are for rainfed crops without climate change.

ranges from 1.41 to 2.36 with an aggregate trend of 1.73 . For both RAPs, the other crops cost trend is assumed the same as the aggregate price trend.

The future herd sizes are larger by $35 \%$ in RAP 4 but do not change in RAP 5, as there is relatively less crop-livestock integration in RAP 5 than in RAP 4. Similar to farm size, the relative variation in herd sizes increases in both RAPs, but to a larger degree in RAP 5. The IMPACT model does not provide milk yield predictions. As such, yield trends from Core Question 2 are assumed (these are referred to as relative yields in Core Question 2). These yield trends are estimated in Shikuku et al. (2017) and represent yield changes as a result of improved feeding for local breed cows. For each RAP, the yield trends are the same because management improvements are similar between the two pathways.

The yield increase of 36\% is predicted by Shikuku et al. (2017) for the wet season and is applied to high and medium MPZs (the wetter areas of Kenya); while the yield increase of 50\% is simulated for the dry season and is applied to the low MPZs (the drier areas of Kenya). Moreover, the high and medium MPZs use more purchased feed than the low MPZs in the current time period and, as such, are expected to have less milk yield improvement from future management changes. The future milk price is predicted with IMPACT model trends. Without climate change, the IMPACT milk price trend is 1.21 in RAP 4 and 1.12 in RAP 5. These trends are both slightly higher for the scenario with climate change: 1.23 in RAP 4 and 1.14 in RAP 5.

Additionally, milk cost is expected to increase with changes in management and input prices. Future milk cost is modeled under the assumption that it increases in proportion to milk yield and price trends for both RAPs, which leads to a cost trend for the high and medium MPZs and a separate cost trend for the low MPZs. 


\section{Crop simulation results}

The DSSAT crop model is used to simulate maize yields under each RAP and under the current and future climate. Table 12 shows statistics on the relative yields for each MPZ under RAP 4. The RCP 4.5 GCMs are used to model future climate with RAP 4. The relative yield is the ratio of the maize yield under the future climate with future management (CM5) compared to the maize yield under the current climate with future management (CM4), for a given farm. Future management details used to simulate future yields with and without climate change are described in Table 13. The CM4 and CM5 yields are 30 year averages from the crop model simulations. A relative yield of 1 indicates no climate impact on yield and a value below (above) 1 indicates a negative (positive) climate impact.

In the low MPZs, the average relative yields are generally close to 1 across all the GCMs, indicating small climate impacts on future maize production. The highest average relative yield is 1.06 and occurs in the cool/wet GCM, while the lowest average relative yield is 0.95 and occurs in the hot/dry GCM. Climate impacts in the medium MPZs are slightly negative in four of the five GCMs, on average. The middle GCM is associated with the highest relative yield (1.02) and the hot/dry GCM is associated with the lowest relative yield (0.92).

The high MPZ is predicted to have average relative yields close to 1 in all GCMs except the hot/dry scenario. These relative yields for this area of Kenya have a larger range across the five GCMs than the low and medium MPZs, with average relative yields ranging from 0.83 (hot/dry) to 1.05 (cool/wet).

Under RAP 5, future climate is modeled using five RCP 8.5 GCMs. Similar to RAP 4, RAP 5 yields are simulated using future management for both the current and future climate. The relative yield statistics for these crop simulations are shown in Table 17. Across Kenya, the DSSAT model predicts negative climate impacts on maize yields under RAP 5. In the low MPZs, the average relative yields are slightly below 1 (0.94-0.99) in four of the GCMs. The lowest relative yield of 0.87 occurs in the hot/dry GCM. The medium and high MPZs are predicted to have the lowest yield impacts in the cool/dry GCM and the highest yield impacts in the hot/dry GCM. The average relative yields range from 0.84 to 0.98 in the medium MPZs and from 0.72 to 0.99 in the high MPZs.

The relative yield predictions in Tables 12 and 17 indicate that maize yields are more susceptible to climate change in RAP 5 than RAP 4. This result is due to two factors. First, changes in climate are less extreme in RAP 4 because it is characterized with a lower emissions scenario than RAP 5. Second, RAP 4 is associated with the use of more sustainable agricultural practices than RAP 5. This characteristic is represented by soil degradation and lower manure application (compared to RAP 4) in RAP 5 crop simulations. As such, climate change has a greater impact on maize 
Table 17. DSSAT relative yields by Maize Potential Zone (MPZ), RAP 5 (RCP 8.5).

\begin{tabular}{|c|c|c|c|c|c|c|c|}
\hline & & \multicolumn{2}{|c|}{ Low Potential } & \multicolumn{2}{|c|}{ Medium Potential } & \multicolumn{2}{|c|}{ High Potential } \\
\hline & & Mean & CV $(\%)$ & Mean & CV $(\%)$ & Mean & $\mathrm{CV}(\%)$ \\
\hline \multirow[t]{5}{*}{ GCM characterization } & Cool/wet & 0.99 & 17.1 & 0.94 & 5.9 & 0.97 & 11.5 \\
\hline & Cool/dry & 0.96 & 11.4 & 0.98 & 4.7 & 0.99 & 7.9 \\
\hline & Middle & 0.94 & 11.7 & 0.94 & 7.2 & 0.86 & 15.1 \\
\hline & Hot/wet & 0.97 & 21.8 & 0.89 & 8.3 & 0.91 & 15.5 \\
\hline & Hot/dry & 0.87 & 10.3 & 0.84 & 13.0 & 0.72 & 26.3 \\
\hline
\end{tabular}

yields in a future that resembles RAP 5. Similarly, both RAP 4 and RAP 5 production systems are most negatively impacted in the hot/dry GCM. This result is true for each MPZ in Kenya. Future maize yields, as predicted by systems of RAP 4 and RAP 5, are most negatively impacted by relatively hotter and drier future climates.

\section{Economic analysis - Background}

The economic analysis for Core Question 3 follows a similar methodology as that of Core Question 1. The TOA-MD model is used to estimate climate change impacts on household farm net returns under each RAP. The first step in the analysis is to calculate the parameters for the future maize-based systems without climate change. These calculations follow the AGMIP methodology and use the trends from Table 14. All monetary values are shown in $2007 \mathrm{KSh}$. Table 18 shows the average household size, farm size, and off-farm income for the current period, RAP 4, and RAP 5 across the strata. As mentioned above, household sizes are smaller, farm sizes are larger, and off-farm income is higher in RAP 4 than in the current period. In RAP 5, household sizes are larger, average farm size is the same, and off-farm income is higher than in the current period.

For each RAP, the economic analysis includes two price scenarios. The first price scenario assumes the IMPACT price trends with and without climate change. This scenario is referred to as the high price scenario since IMPACT price trends indicate higher future prices. The second scenario, called the low price scenario, assumes that prices in the future without climate change are the same as the current period. For the price with climate change, the low price scenario uses the ratio of the price with climate change to the price without climate change from the IMPACT model. For maize, this ratio is 1.60 divided by 1.51 and equals 1.06 ; as such, the maize price with climate change is calculated with 1.06 as the trend in the low price scenario. This approach is utilized for other crops and milk as well. Table 19 shows the price trends used for each price scenario. 
Table 18. Average household size, farm size, and off-farm income for current and future (2050) periods.

\begin{tabular}{|c|c|c|c|c|c|c|c|c|c|c|}
\hline \multirow[b]{2}{*}{ Strata } & \multirow[b]{2}{*}{ Obs } & \multicolumn{3}{|c|}{ Current Period } & \multicolumn{3}{|c|}{ RAP 4} & \multicolumn{3}{|c|}{ RAP 5} \\
\hline & & $\begin{array}{l}\text { HH } \\
\text { size }\end{array}$ & $\begin{array}{c}\text { Farm } \\
\text { Size (ha) }\end{array}$ & $\begin{array}{c}\text { Off-farm } \\
\text { Income } \\
(\text { Ksh })\end{array}$ & $\begin{array}{l}\text { HH } \\
\text { size }\end{array}$ & $\begin{array}{c}\text { Farm } \\
\text { Size (ha) }\end{array}$ & $\begin{array}{c}\text { Off-farm } \\
\text { Income } \\
\text { (Ksh) }\end{array}$ & HH size & $\begin{array}{c}\text { Farm } \\
\text { Size (ha) }\end{array}$ & $\begin{array}{c}\text { Off-farm } \\
\text { Income } \\
\text { (Ksh) }\end{array}$ \\
\hline Low & 165 & 5.0 & 1.6 & 70,216 & 4.0 & 2.2 & $1,05,324$ & 6.0 & 1.6 & $1,26,389$ \\
\hline Low-milk & 73 & 4.8 & 2.1 & 87,125 & 3.9 & 2.9 & $1,30,687$ & 5.8 & 2.1 & $1,56,824$ \\
\hline Medium & 142 & 4.8 & 1.1 & 44,749 & 3.9 & 1.6 & 67,123 & 5.8 & 1.1 & 80,548 \\
\hline Medium-milk & 259 & 4.5 & 1.3 & 63,343 & 3.6 & 1.9 & 95,014 & 5.4 & 1.3 & $1,14,017$ \\
\hline High & 65 & 5.8 & 1.2 & 49,118 & 4.7 & 1.6 & 73,677 & 7.0 & 1.2 & 88,412 \\
\hline High-milk & 170 & 5.5 & 1.9 & 76,464 & 4.4 & 2.7 & $1,14,696$ & 6.6 & 1.9 & $1,37,635$ \\
\hline
\end{tabular}


Table 19. Activity price trends (relative to current prices) for each RAP and price scenario.

\begin{tabular}{|c|c|c|c|c|c|c|c|c|}
\hline & \multicolumn{4}{|c|}{ RAP 4} & \multicolumn{4}{|c|}{ RAP 5} \\
\hline & \multicolumn{2}{|c|}{ Low Price } & \multicolumn{2}{|c|}{ High Price } & \multicolumn{2}{|c|}{ Low Price } & \multicolumn{2}{|c|}{ High Price } \\
\hline & $\begin{array}{c}\text { Without } \\
\text { CC }\end{array}$ & With CC & $\begin{array}{c}\text { Without } \\
\text { CC }\end{array}$ & With CC & $\begin{array}{c}\text { Without } \\
\text { CC }\end{array}$ & With CC & $\begin{array}{c}\text { Without } \\
\text { CC }\end{array}$ & With CC \\
\hline Maize & 1 & 1.06 & 1.51 & 1.60 & 1 & 1.15 & 1.37 & 1.57 \\
\hline Other crops & 1 & 1.19 & 1.18 & 1.41 & 1 & 1.28 & 1.35 & 1.73 \\
\hline Milk & 1 & 1.02 & 1.21 & 1.23 & 1 & 1.02 & 1.12 & 1.14 \\
\hline
\end{tabular}

\section{RAP 4 Economic analysis - Results}

Table 20 shows select economic results for RAP 4, RCP 4.5, both price scenarios, and the assumption that all activities (i.e., other crops and livestock) are impacted by climate the same as maize (referred to as "Maize Impact on All Activities" in the table title). The table shows results for the climate-price scenarios that yield the least and most vulnerable households, in aggregate. The cool/wet GCM and high price scenario is associated with the lowest proportion of households negatively impacted by climate change, while the hot/dry GCM and high price scenario is associated with the highest amount. In both scenarios, the majority of households are not vulnerable to climate change in RAP 4 under this relative yield assumption.

In particular, the total percentage of vulnerable households ranges from $35.2 \%$ to $47.2 \%$ across RAP 4 scenarios under this relative yield assumption. Economic simulations predict mostly positive net economic impacts, higher per capita income, and lower poverty with climate change for maize farms in Kenya. However, farms in the high MPZ have predictions of negative net economic impacts in the hot/dry GCM and high price scenario. In this scenario, $58.4 \%$ of farms without milk in the high MPZ are vulnerable and $56.9 \%$ of farms with milk in this MPZ are vulnerable to climate change.

The range of RAP 4 results for both price scenarios under the assumption that only maize is impacted by climate are displayed in Table 21. These simulations predict that there is low vulnerability to climate change under RAP 4 and RCP 4.5. The percentage of vulnerable households ranges from $36.8 \%$ in the cool/wet GCM and high price scenario to $40.1 \%$ in the hot/dry GCM and high price scenario. Across the five GCMs and two price scenarios, per capita income is higher and poverty is lower with climate change.

Similar to Table 22, the high potential farms are predicted to be more vulnerable to climate change than the low and medium potential farms. However, with the assumption that only maize is impacted by climate change, the hot/dry GCM and high price scenario do not yield negative net economic impacts, as is the case when 
Table 20. Range of economic results - RAP 4, RCP 4.5, maize impact on all activities.

\begin{tabular}{|c|c|c|c|c|c|c|c|c|c|c|c|c|}
\hline \multirow[b]{2}{*}{ Strata } & \multicolumn{6}{|c|}{ Least Vulnerable } & \multicolumn{6}{|c|}{ Most Vulnerable } \\
\hline & GCM & Price & $\begin{array}{c}\text { Vulnera } \\
(\%)\end{array}$ & $\begin{array}{c}\text { Net } \\
\text { Impact } \\
(\%)\end{array}$ & $\begin{array}{c}\text { Change } \\
\text { in PCI } \\
(\%)\end{array}$ & $\begin{array}{c}\text { Change } \\
\text { in } \\
\text { Poverty } \\
\text { Rate }(\%)\end{array}$ & GCM & Price & $\begin{array}{c}\text { Vulneral } \\
(\%)\end{array}$ & $\begin{array}{c}\text { Net } \\
\text { le Impact } \\
(\%)\end{array}$ & $\begin{array}{c}\text { Change } \\
\text { in PCI } \\
(\%)\end{array}$ & $\begin{array}{c}\text { Change } \\
\text { in } \\
\text { Poverty } \\
\text { Rate }(\%)\end{array}$ \\
\hline Low & Cool/wet & High & 34.3 & 14.7 & 9.2 & -2.3 & Hot/dry & High & 42.8 & 5.8 & 3.6 & -1.0 \\
\hline Low-milk & Cool/wet & High & 27.2 & 20.6 & 13.4 & -2.4 & Hot/dry & High & 39.9 & 6.9 & 4.6 & -0.9 \\
\hline Medium & Cool/wet & High & 39.6 & 10.0 & 9.9 & -1.2 & Hot/dry & High & 43.5 & 6.0 & 5.9 & -0.7 \\
\hline Medium-milk & Cool/wet & High & 39.1 & 9.3 & 9.6 & -0.3 & Hot/dry & High & 44.0 & 4.9 & 5.0 & 0.0 \\
\hline High & Cool/wet & High & 38.1 & 12.7 & 10.9 & -2.4 & Hot/dry & High & 58.4 & -7.4 & -6.4 & 2.5 \\
\hline High-milk & Cool/wet & High & 32.6 & 12.4 & 11.9 & -0.9 & Hot/dry & High & 56.9 & -4.1 & -3.9 & 1.3 \\
\hline Aggregate & Cool/wet & High & 35.2 & 11.4 & 10.4 & -1.3 & Hot/dry & High & 47.2 & 2.3 & 2.5 & 0.1 \\
\hline
\end{tabular}


Table 21. Range of economic results - RAP 4, RCP 4.5, no impact on non-maize activities.

\begin{tabular}{|c|c|c|c|c|c|c|c|c|c|c|c|c|}
\hline \multirow[b]{2}{*}{ Strata } & \multicolumn{6}{|c|}{ Least Vulnerable } & \multicolumn{6}{|c|}{ Most Vulnerable } \\
\hline & GCM & Price & $\begin{array}{c}\text { Vulnera } \\
(\%)\end{array}$ & $\begin{array}{c}\text { Net } \\
\text { Impact } \\
(\%)\end{array}$ & $\begin{array}{c}\text { Change } \\
\text { in PCI } \\
(\%)\end{array}$ & $\begin{array}{c}\text { Change } \\
\text { in } \\
\text { Poverty } \\
\text { Rate }(\%)\end{array}$ & GCM & Price & $\begin{array}{c}\text { Vulnerab } \\
(\%)\end{array}$ & $\begin{array}{c}\text { Net } \\
\text { Impact } \\
(\%)\end{array}$ & $\begin{array}{c}\text { Change } \\
\text { in PCI } \\
(\%)\end{array}$ & $\begin{array}{c}\text { Change } \\
\text { in } \\
\text { Poverty } \\
\text { Rate }(\%)\end{array}$ \\
\hline Low & Cool/wet & High & 36.6 & 12.4 & 6.7 & -2.1 & Hot/dry & High & 38.4 & 10.6 & 5.7 & -1.8 \\
\hline Low-milk & Cool/wet & High & 36.8 & 9.6 & 5.6 & -1.5 & Hot/dry & High & 38.4 & 8.3 & 4.8 & -1.3 \\
\hline Medium & Cool/wet & High & 37.6 & 12.8 & 11.8 & -2.2 & Hot/dry & High & 37.8 & 12.6 & 11.6 & -2.1 \\
\hline Medium-milk & Cool/wet & High & 37.1 & 11.8 & 11.4 & -0.7 & Hot/dry & High & 37.4 & 11.5 & 11.1 & -0.7 \\
\hline High & Cool/wet & High & 38.6 & 12.2 & 9.0 & -3.0 & Hot/dry & High & 48.7 & 1.2 & 0.9 & -0.2 \\
\hline High-milk & Cool/wet & High & 35.8 & 10.0 & 8.6 & -1.3 & Hot/dry & High & 44.4 & 3.7 & 3.2 & -0.2 \\
\hline Aggregate & Cool/wet & High & 36.8 & 11.5 & 9.8 & -1.6 & Hot/dry & High & 40.1 & 9.1 & 8.0 & -1.0 \\
\hline
\end{tabular}


Table 22. Impact of technological intervention on average maize and milk returns — RAP 4.

\begin{tabular}{|c|c|c|c|c|c|c|}
\hline \multirow[b]{2}{*}{ Strata } & \multirow[b]{2}{*}{ GCM } & \multirow[b]{2}{*}{ Price Scenario } & \multicolumn{2}{|c|}{$\begin{array}{c}\text { Change in } \\
\text { Maize Net } \\
\text { Returns }\end{array}$} & \multicolumn{2}{|c|}{$\begin{array}{l}\text { Change in } \\
\text { Milk Net } \\
\text { Returns }\end{array}$} \\
\hline & & & (Ksh) & $(\%)$ & (Ksh) & $(\%)$ \\
\hline Low & Cool/wet & High & 7,945 & 28.6 & $2,18,424$ & - \\
\hline Low-milk & Cool/wet & High & 2,854 & 12.1 & $2,36,705$ & 543.4 \\
\hline Medium & Cool/wet & High & 4,733 & 20.1 & 76,484 & - \\
\hline Medium-milk & Cool/wet & High & 4,834 & 17.8 & 76,928 & 249.0 \\
\hline High & Cool/wet & High & 11,452 & 13.3 & 70,031 & - \\
\hline High-milk & Cool/wet & High & 20,469 & 15.2 & 71,400 & 157.7 \\
\hline
\end{tabular}

all activities are impacted by climate. The only stratum that is predicted to have negative net economic impacts for any GCM is the high MPZ without milk. This outcome occurs in the hot/dry GCM for the high price scenario (51.5\% vulnerable and $-1.3 \%$ net impact).

Stratum-level results for all RAP 4 simulations are shown in the box and whisker format in Figs. 7 and 8. The percentage of vulnerable households in each stratum across the price and relative yield scenarios (vertical axis) for each GCM (horizontal axis) are shown in Fig. 7. In each figure, the left graph references farms without milk and the right graph references farms with milk. In the low and medium MPZs, less than $50 \%$ of households are predicted vulnerable to climate change across all GCMs. The predicted percentages are in the $25 \%-45 \%$ range and the hot/dry scenario tends to yield the highest percentage of vulnerable households across the four strata. In the high MPZ (Fig. 7:), the hot/dry GCM produces higher rates of vulnerability. In both the strata, the highest prediction of vulnerable households is between 55\% and 60\%. However, the other four GCMs do not predict above $50 \%$ vulnerable households in any scenario; these predictions range from $30 \%$ to $45 \%$.

The predicted net impacts on mean farm net returns for all simulations across the different strata are shown in Fig. 8. These graphs show the predicted net impacts for each price and relative yield scenario (vertical axis) across the climate scenarios (horizontal axis). In addition, there is a red line at $0 \%$ to serve as a reference on each graph. In each figure, the left graph shows the predictions for the farms without milk in the region and the right graph shows the predictions for the farms with milk in the region. Predicted net economic impacts in the low and medium MPZs are positive for all simulations. Moreover, the lowest predicted increase in mean farm net returns is around 5\% occurring in the hot/dry GCM, while the highest predictions tend to be in the $15 \%-20 \%$ range and the GCM varies across the strata. Meanwhile, the 

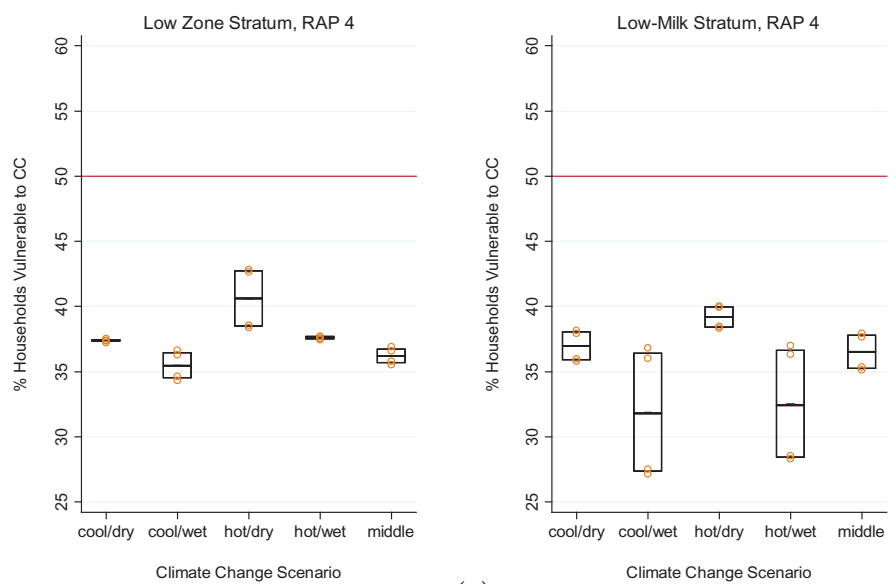

(a)
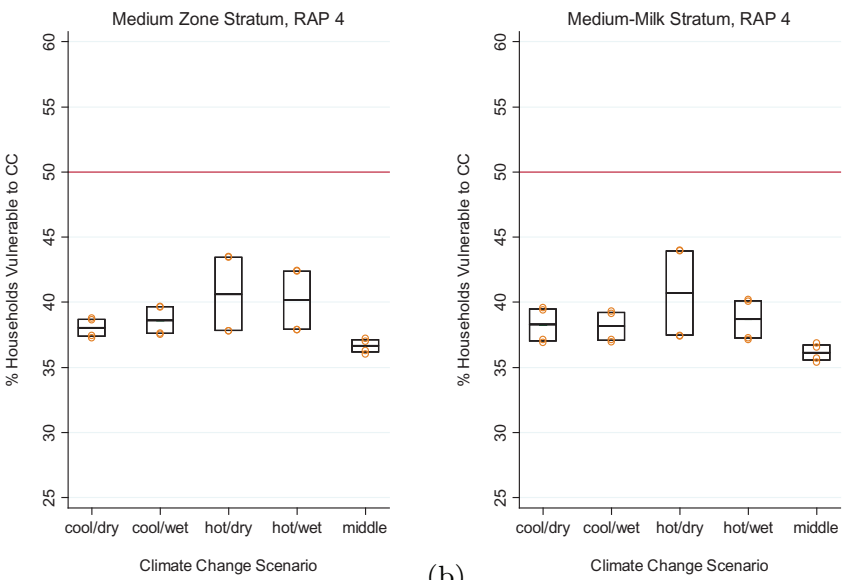

(b)
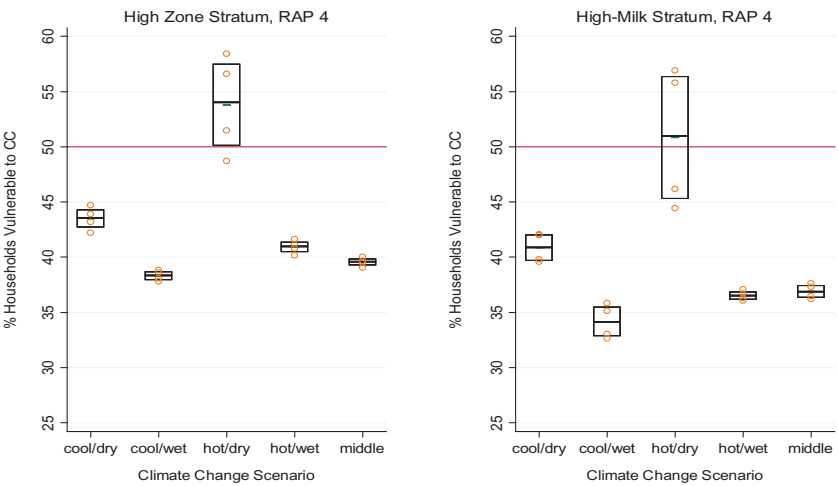

(c)

Fig. 7. Percentage of vulnerable households by strata under RAP 4. Low MPZ (a), Medium MPZ (b), High MPZ (c). 

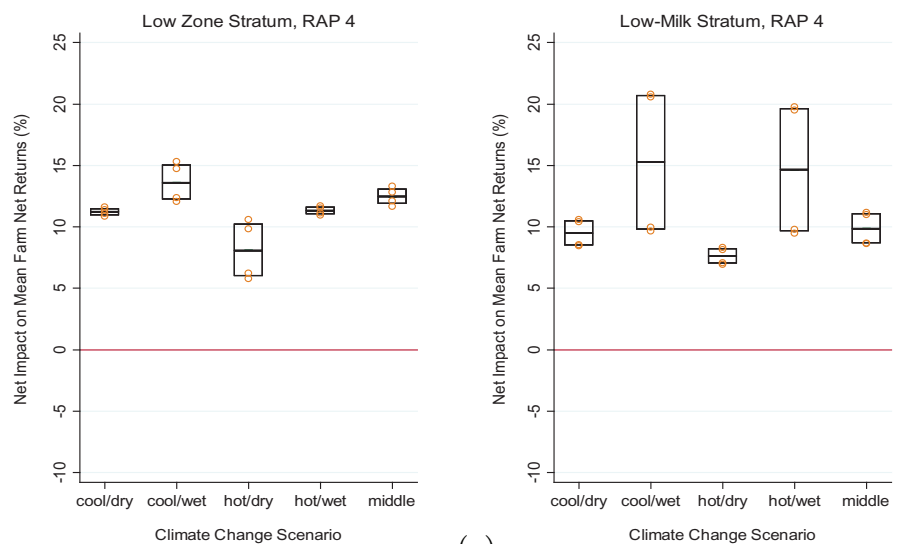

(a)
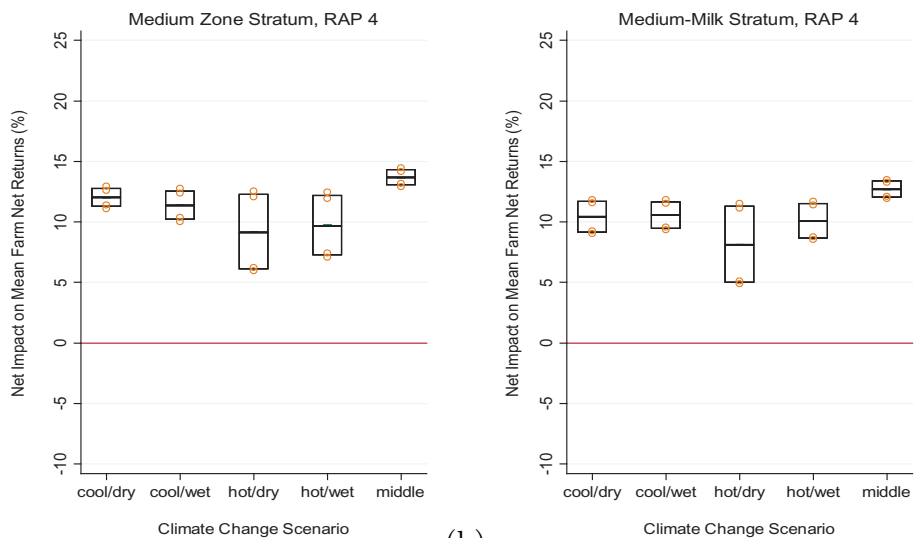

(b)
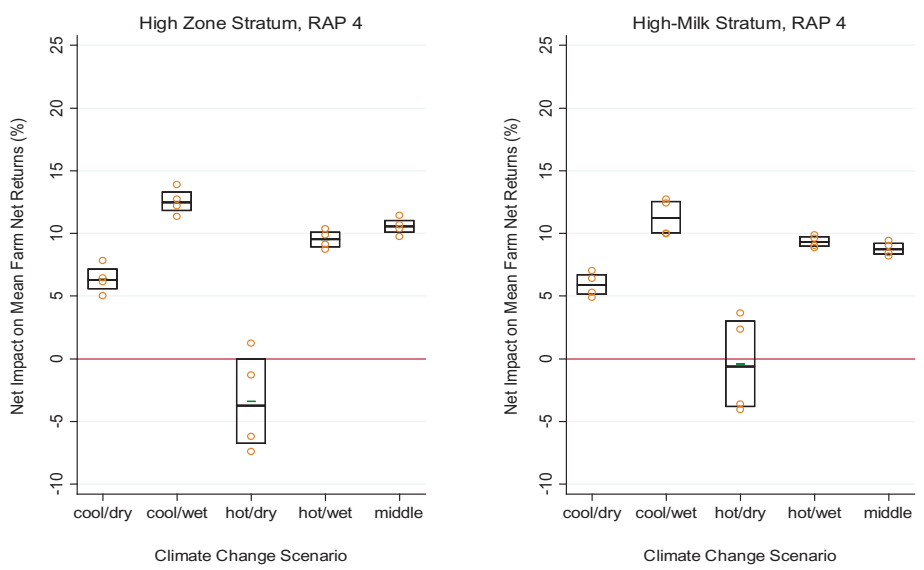

Fig. 8. Impact on net mean farm returns under RAP 4. Low MPZ (a), Medium MPZ (b), High MPZ (c). 
high MPZ farms are predicted to experience negative net impacts on mean farm net returns in a number of the hot/dry scenarios (Fig. 8z). The other climate scenarios predict net economic impacts between $5 \%$ and $15 \%$ for both the strata in the area of Kenya with high maize potential.

\section{RAP 4 Economic analysis - Discussion}

In most of the scenarios simulated, climate change is predicted to have a positive impact on the future maize-based systems of RAP 4. This result requires further explanation because the climate impact on maize yields is negative in a number of GCMs, as indicated by average relative yields below 1 in Table 12. The economic impact of climate change is the result of both biophysical and economic differences between scenarios with and without climate change. Specifically, these biophysical differences are represented by relative yields that differ from 1 and these economic differences are represented by price changes (shown in Table 23 ).

The IMPACT model predicts that the maize prices are $6 \%$ higher with climate change, other crop prices are 19\% higher with climate change, and milk prices are $2 \%$ higher with climate change for RAP 4. In certain GCMs and MPZs, the average relative yields are at or above 1 and with higher prices the predicted climate impacts are positive, on average. In most of the scenarios where the average relative yields are below 1, the increase in prices with climate change is large enough to offset the lower yields and the end results are positive economic impacts.

\section{RAP 5 Economic analysis - Results}

Table 15 displays the range of aggregate economic outcomes for RAP 5, RCP 8.5, under the assumption that all activities have the same relative yields as maize, and it includes results for both price scenarios. Across the Kenyan MPZs ("Aggregate" row in tables), the amount of vulnerable households is predicted between $34.0 \%$ (cool/dry GCM and high price) and 51.2\% (hot/dry GCM and low price) for the simulated climate-price scenarios in RAP 5. In most scenarios, the economic model predicts positive net economic impacts, higher per capita income, and lower poverty rates in a RAP 5 future with climate change, compared to a future without climate change.

One noticeable difference from these results and those for RAP 4 is that the hot/dry GCM yields a slight majority of households (50.7\% high price, $51.2 \%$ low price) vulnerable to climate change and an increase in the poverty rate $(0.3 \%$ high price, $0.2 \%$ low price). Looking at the strata-level results, farms in the high MPZ are the only sub-populations with predicted negative net economic impacts for any future scenario. In the hot/dry GCM and low price scenario, $62.8 \%$ of farms without 
Table 23. Range of economic results - impact of technological intervention, RAP 4.

\begin{tabular}{|c|c|c|c|c|c|c|c|c|c|c|c|c|}
\hline \multirow[b]{3}{*}{ Strata } & \multicolumn{6}{|c|}{ Lowest \% Better Off } & \multicolumn{6}{|c|}{ Highest \% Better Off } \\
\hline & \multirow[b]{2}{*}{ GCM } & \multirow{2}{*}{$\begin{array}{l}\text { Price } \\
\text { Sce- } \\
\text { nario }\end{array}$} & \multirow[b]{2}{*}{$\begin{array}{l}\text { Interventio } \\
\text { Adoption } \\
\text { Rate }(\%)\end{array}$} & \multirow{2}{*}{$\begin{array}{c}\text { Change } \\
\text { n in Net } \\
\text { Returns } \\
(\%)\end{array}$} & \multirow[b]{2}{*}{$\begin{array}{c}\text { Change } \\
\text { in PCI } \\
(\%)\end{array}$} & \multirow{2}{*}{$\begin{array}{c}\text { Change } \\
\text { in } \\
\text { Poverty } \\
\text { Rate } \\
(\%)\end{array}$} & \multirow[b]{2}{*}{ GCM } & \multirow[b]{2}{*}{$\begin{array}{l}\text { Price } \\
\text { Sce- } \\
\text { nario }\end{array}$} & \multirow[b]{2}{*}{$\begin{array}{c}\text { Interventio } \\
\text { Adoption } \\
\text { Rate }(\%)\end{array}$} & & \multirow{2}{*}{$\begin{array}{c}\text { Change } \\
\text { in PCI } \\
(\%)\end{array}$} & \multirow{2}{*}{$\begin{array}{c}\text { Change } \\
\text { in } \\
\text { Poverty } \\
\text { Rate } \\
(\%)\end{array}$} \\
\hline & & & & & & & & & & $\begin{array}{c}\text { n in Net } \\
\text { Returns } \\
(\%)\end{array}$ & & \\
\hline Low & Middle & High & 87.0 & 222 & 111.2 & -9.6 & Cool/wet & High & 87.2 & 222 & 112.0 & -9.5 \\
\hline Low-milk & Middle & High & 82.6 & 171 & 88.4 & -5.3 & Cool/wet & High & 82.8 & 168 & 91.6 & -4.6 \\
\hline Medium & Middle & High & 78.8 & 47 & 35.4 & -7.3 & Cool/wet & High & 78.6 & 47 & 35.1 & -7.6 \\
\hline Medium-milk & Middle & High & 70.8 & 33 & 25.8 & -3.8 & Cool/wet & High & 71.2 & 34 & 25.9 & -3.9 \\
\hline High & Middle & High & 77.5 & 46 & 30.2 & -8.4 & Cool/wet & High & 82.8 & 61 & 40.6 & -9.5 \\
\hline High-milk & Middle & High & 72.5 & 29 & 20.8 & -2.9 & Cool/wet & High & 77.4 & 34 & 25.1 & -3.3 \\
\hline Aggregate & Middle & High & 77.1 & 57 & 40.5 & -5.8 & Cool/wet & High & 78.7 & 61 & 42.6 & -5.9 \\
\hline
\end{tabular}


milk and $65.7 \%$ of farms with milk are vulnerable to climate change. In this scenario, farms without (with) milk are predicted to have net economic impacts of $-11.7 \%$ $(-9.5 \%)$, a $5.8 \%(6.0 \%)$ decrease in per capita income, and a $2.6 \%$ (2.8\%) increase in poverty.

The range of RAP 5 results for all scenarios with the assumption that only maize is impacted by climate are displayed in Table 24 . With this relative yield assumption on non-maize activities, the economic simulations predict that the majority of Kenyan maize farms are not vulnerable to climate change in RAP 5 scenarios. Across the five GCMs and two price scenarios, aggregate per capita income is higher (between 8.0\% and $12.0 \%$ ) and poverty is lower (between $-2.3 \%$ and $-3.2 \%$ ) with climate change. The lowest proportion of vulnerable households, in aggregate, is predicted in the $\mathrm{cool} / \mathrm{dry}$ GCM and high price scenario (32.9\%) and the highest amount is predicted in the hot/dry GCM and low price scenario (38.0\%). The high MPZ farmers without milk are the only group predicted to have negative net economic impacts in the most vulnerable scenario: $50.8 \%$ of these farms are predicted to be vulnerable with net economic impacts of $-0.7 \%$. Similar to RAP 4 , the difference between the relative yield assumptions is that the range of economic impacts is larger when all activities are impacted.

Figure 9 displays the percentage of vulnerable households in each stratum across the price and relative yield scenarios (vertical axis) for each GCM (horizontal axis) under RAP 5. In each figure, the left graph references farms without milk and the right graph references farms with milk. Similar to RAP 4, less than $50 \%$ of households in the low and medium MPZs are predicted vulnerable to climate change across all GCMs, price scenarios, and relative yield assumptions. The predicted percentages are $25 \%-45 \%$ in the low MPZ and 30\%-50\% in the medium MPZ. The scenarios with the most vulnerable households in each stratum tend to occur in the hot/dry climate scenario. In the high MPZ (Fig. 9z), the hot/dry GCM yields predictions where a majority of farms are vulnerable to climate change. The highest percentage of vulnerable households is close to $65 \%$ for both strata. The other four climate scenarios have no predictions above 50\% vulnerable households; although the middle GCM yields predictions close to $50 \%$ in a number of scenarios for each stratum.

The predicted net impacts on mean farm net returns for RAP 5 simulations are shown in Fig. 10. The vertical axis of each graph shows the predicted net impacts for each price and relative yield scenario and the horizontal axis shows each climate scenario. The red line at $0 \%$ serves as a reference for net impacts being positive or negative. In each figure, predictions for farms without milk are in the left graph and predictions for farms with milk are in the right graph. Across all RAP 5 scenarios, net economic impacts are predicted to be positive for the low (5\%-25\%) and medium $(0 \%-20 \%)$ MPZs. The lowest predicted net economic impacts coincide with the 
Table 24. Range of economic results - RAP 5, RCP 8.5, no impact on non-maize activities.

\begin{tabular}{|c|c|c|c|c|c|c|c|c|c|c|c|c|}
\hline \multirow[b]{2}{*}{ Strata } & \multicolumn{6}{|c|}{ Least Vulnerable } & \multicolumn{6}{|c|}{ Most Vulnerable } \\
\hline & GCM & Price & $\begin{array}{c}\text { Vulnerab } \\
(\%)\end{array}$ & $\begin{array}{c}\text { Net } \\
\text { Impact } \\
(\%)\end{array}$ & $\begin{array}{c}\text { Change } \\
\text { in PCI } \\
(\%)\end{array}$ & $\begin{array}{c}\text { Change } \\
\text { in } \\
\text { Poverty } \\
\text { Rate }(\%)\end{array}$ & GCM & Price & $\begin{array}{c}\text { Vulneral } \\
(\%)\end{array}$ & $\begin{array}{c}\text { Net } \\
\text { le Impact } \\
(\%)\end{array}$ & $\begin{array}{c}\text { Change } \\
\text { in PCI } \\
(\%)\end{array}$ & $\begin{array}{c}\text { Change } \\
\text { in } \\
\text { Poverty } \\
\text { Rate }(\%)\end{array}$ \\
\hline Low & Cool/dry & High & 33.5 & 16.6 & 7.3 & -3.0 & Hot/dry & Low & 35.0 & 15.0 & 5.1 & -2.2 \\
\hline Low-milk & Cool/dry & High & 32.6 & 14.0 & 7.5 & -2.6 & Hot/dry & Low & 34.8 & 11.9 & 5.3 & -2.1 \\
\hline Medium & Cool/dry & High & 33.0 & 19.0 & 15.5 & -5.1 & Hot/dry & Low & 34.1 & 18.0 & 12.6 & -4.9 \\
\hline Medium-milk & Cool/dry & High & 32.5 & 17.4 & 15.0 & -2.4 & Hot/dry & Low & 33.9 & 16.0 & 12.2 & -2.8 \\
\hline High & Cool/dry & High & 36.5 & 14.2 & 8.9 & -4.1 & Hot/dry & Low & 50.8 & -0.7 & -0.4 & 0.1 \\
\hline High-milk & Cool/dry & High & 32.1 & 12.5 & 9.3 & -2.9 & Hot/dry & Low & 45.2 & 3.1 & 1.9 & -0.7 \\
\hline Aggregate & Cool/dry & High & 32.9 & 16.1 & 12.0 & -3.2 & Hot/dry & Low & 38.0 & 12.3 & 8.0 & -2.3 \\
\hline
\end{tabular}



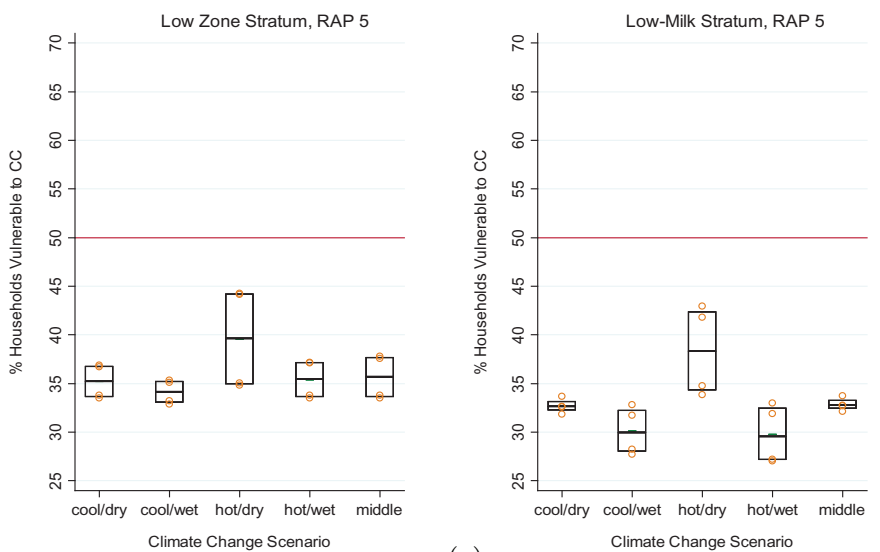

(a)
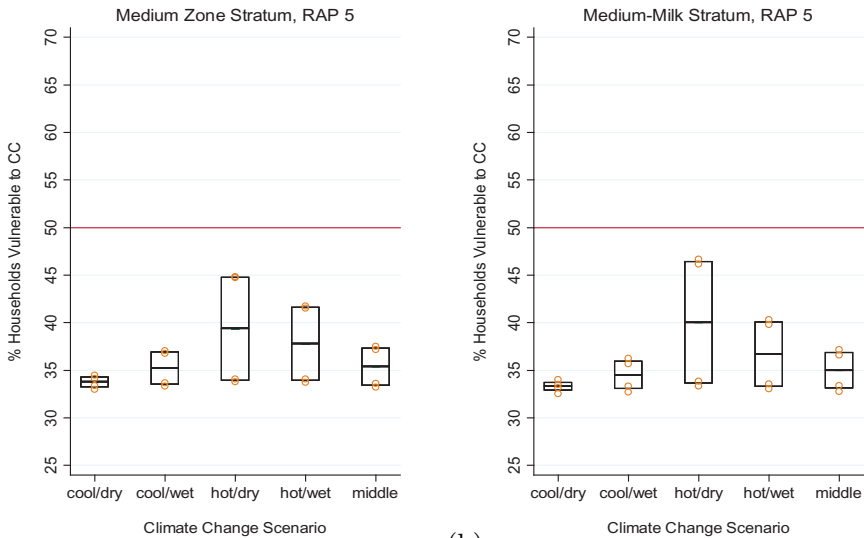

(b)
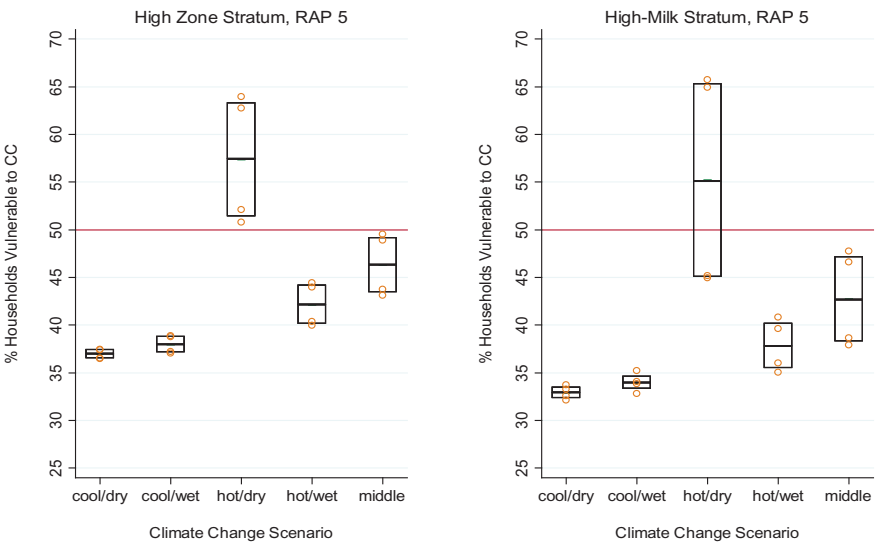

(c)

Fig. 9. Percentage of vulnerable households by strata under RAP 5. Low MPZ (a), Medium MPZ (b), High MPZ (c). 

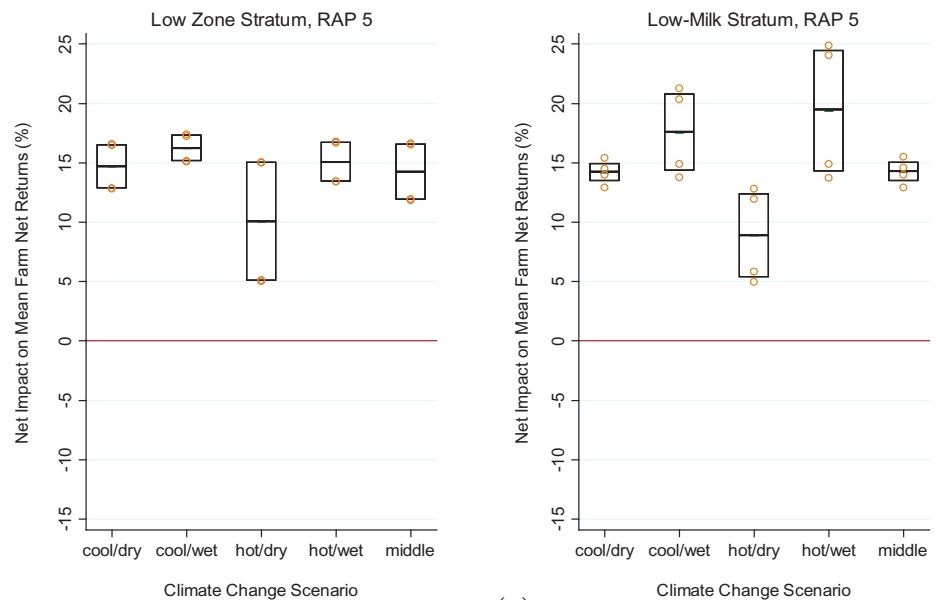

(a)
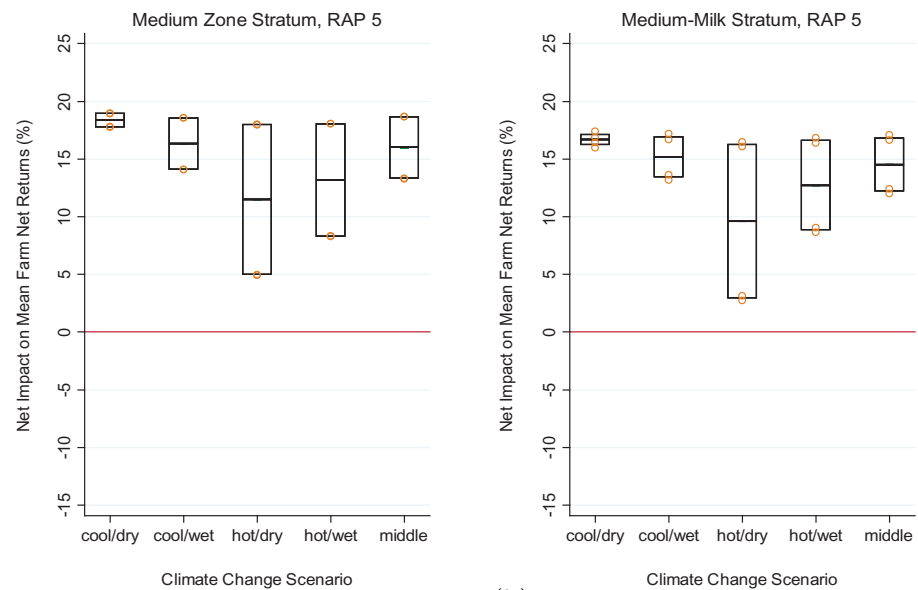

(b)
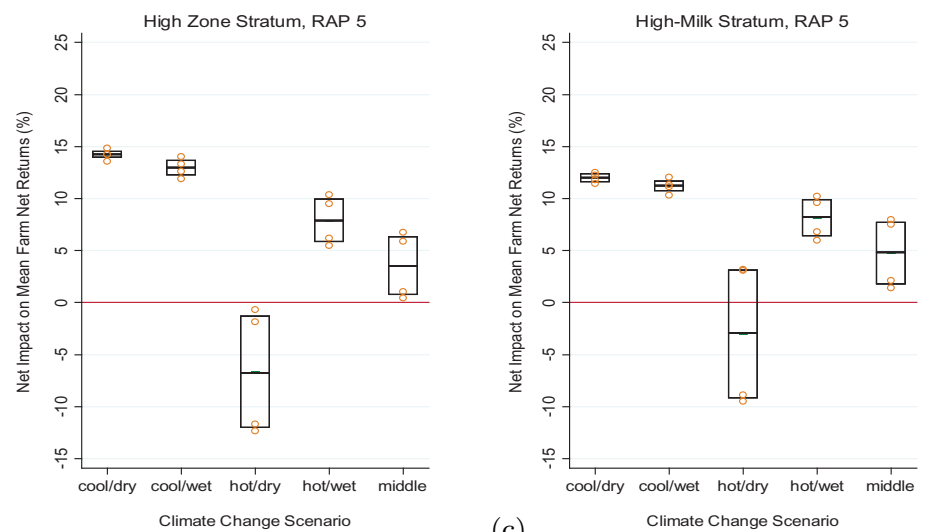

Fig. 10. Impact on net mean farm returns under RAP 5. Low MPZ (a), Medium MPZ (b), High MPZ (c). 
highest prediction of vulnerable households and tend to occur in scenarios with the hot/dry GCM for each stratum. Meanwhile, the high MPZ farms are predicted to experience negative net impacts on mean farm net returns in a number of the hot/dry scenarios (Fig. 10z). In these particular scenarios, the results predict that mean farm net returns are reduced around $12 \%$ for farms without milk and $10 \%$ for farms with milk. The other climate scenarios predict positive net economic impacts up to $15 \%$ for both the strata in this area of Kenya.

\section{RAP 5 Economic analysis - Discussion}

In most scenarios and strata, the predicted economic impacts from climate change are positive in RAP 5. As discussed with the RAP 4 results, the climate impacts are the result of both economic and biophysical differences between scenarios with and without climate change. From a biophysical standpoint, the crop model simulations predict that climate has a negative impact on maize yields for each MPZ in RAP 5, on average (Table 17). Similar to RAP 4, maize, other crops, and milk prices are predicted to be higher with climate change than without climate change in RAP 5 (Table 23). The IMPACT model predicts the climate change maize price to be $15 \%$ higher, the other crops price to be $28 \%$ higher, and the milk price to be $2 \%$ higher than the prices without climate change. These higher prices tend to offset the negative climate impact on yields, leading to positive economic impacts.

\section{Economic analysis - Conclusion}

A summary of the economic results provides insights into the climate vulnerability of future maize-based systems in Kenya. Considering the aggregate outcomes, the percentage of households predicted to have lower farm net returns with climate change ranges from $35.2 \%$ to $47.2 \%$ in a future resembling RAP 4 and $32.9 \%$ to $51.2 \%$ in a future resembling RAP 5. These ranges are across all GCMs, relative yield assumptions, and price scenarios. In both RAPs, the per capita income is predicted to increase with climate change. In RAP 4, the per capita income increases between $2.5 \%$ and $10.4 \%$ across all scenarios; in RAP 5, it increases from $0.3 \%$ to $12.0 \%$.

Additionally, as a result of climate change, the poverty rate changes between $-1.7 \%$ and $0.1 \%$ in RAP 4 and $-3.2 \%$ and $0.3 \%$ in RAP 5. These changes are relative to different baseline poverty rates in each RAP. As such, the climate change poverty rates range from $16.3 \%$ to $21.0 \%$ in RAP 4 and from $27.6 \%$ to $36.9 \%$ in RAP 5. The economic results for RAP 4 indicate that the lowest aggregate percentage of vulnerable households occurs in the cool/wet GCM for each price scenario and relative yield assumption. Meanwhile, the cool/dry GCM is associated with the lowest percentage in the RAP 5 price-relative yield scenarios. For both RAPs, regardless of 
the price scenario and relative yield assumption, the hot/dry GCM yields the highest percentage of vulnerable households.

These economic results reflect biophysical changes (e.g., maize yields) and economic changes (e.g., prices) that are associated with climate change. The DSSAT crop model predicts that future maize yields across Kenya (based on production characteristics developed in this study) are negatively impacted by climate in a number of RAP 4 scenarios and most RAP 5 scenarios. The global economic model, IMPACT, predicts that prices in climate change scenarios are higher than prices in scenarios without climate change. The higher prices with climate change tend to offset the negative climate impact on yields, leading to predictions of positive net impacts on mean farm net returns.

However, examining net returns for each activity - maize, other crops, and milk - provides a more detailed understanding of climate change impact on future maize-based systems in Kenya. First, across the strata, there are scenarios where maize and milk net returns decrease as a result of climate change. Notably, the other crops activity is, in almost every scenario and strata, positively impacted by climate change. This result is driven by the other crops price increasing by a relatively large amount in the future scenarios with climate change. With this price increase, the other crops activity provides a buffer against negative climate impacts on yields and leads to increases in mean farm net returns. This narrative applies to every scenario for the farms in the low and medium MPZs.

In the high MPZs, the range of outcomes includes negative net economic impacts of climate change. First, these farms are predicted to be the most negatively impacted from a biophysical standpoint, in the worst-case scenarios, and second, they obtain the most income from maize, which has relatively smaller price increase with climate change. When combined, these two factors yield predictions of lower farm net returns and a majority of households being worse off with climate change in the high MPZ. Despite the aggregate outcomes, the strata-level results predict that climate impacts differ based on location agroecology and household income diversification.

\section{Core Question 4}

\section{Technology intervention for future maize-based systems in Kenya}

This core question analyses the impacts of a technology intervention in the production systems of the future. The technology intervention for future maize-based systems in Kenya is consistent with that of Core Question 2; however, it is tailored to the future world with climate change. The goals of the intervention are to offset negative climate impacts on maize yields and capitalize on the profitability of milk production. Similar to Core Question 3, this analysis is undertaken for future RAPs and their associated climate scenarios. 
In both RAPs, there are future scenarios where average maize net returns are predicted to decrease as a result of climate change across Kenya. These negative economic impacts are the result of decreases in maize yields caused by climate change. As such, the technological intervention aims to increase maize yields in future climate scenarios by increasing fertilizer application for each farm. In terms of milk production, the Core Question 2 analysis indicates that adding improved breed cows may substantially increase milk net returns in current production systems. Adding one improved breed cow to each farm, along with improved feeding strategies, is predicted to more than double milk net returns, on average.

To implement a similar intervention in future production systems, each farm is provided with several improved breed cows. In the low MPZs, farms receive 3 additional cows, while in the medium and high MPZs, farms receive 2 additional cows. Farms receive more cows in the low MPZs because, as part of the RAPs, these farms are assumed to be relatively more focused on milk production in the future. Moreover, this future intervention includes a larger increase in herd size than that of Core Question 2 to reflect a future scenario consistent with the Government of Kenya plans of promoting improved breeds and interventions like the EADD project (Valdivia et al., 2016; Government of Kenya 2013; EADD, 2013, 2014).

With the increase in herd size, farms also apply more manure with the intervention. The only difference between the interventions in RAP 4 and RAP 5 is related to soil improvement. In RAP 5, soil quality is lower than in the current period and, as a result, the intervention includes soil restoration practices that restore soil to its current (2007) quality. Table 25 provides a summary of the Core Question 4 technological intervention for both RAPs.

As Table 25 shows, fertilizer application increases by $25 \mathrm{~N} \mathrm{~kg} / \mathrm{ha}$ for each farm under the intervention. This rate increase is applied in each of the MPZs across Kenya. The resulting fertilizer application rates for each MPZ are shown in Table 27.

Table 25. Technological intervention components.

\begin{tabular}{|c|c|}
\hline Parameters & Description of Change \\
\hline Fertilizer application & Increase by $25 \mathrm{~N}(\mathrm{~kg} / \mathrm{ha})$ for all farms. \\
\hline Manure application & Increase by $1000 \mathrm{~kg} / \mathrm{ha}$ for all farms. \\
\hline Fertilizer price & Decrease by $25 \%$. \\
\hline Soil quality & Restored to current (2007) level. Applies to RAP 5 only. \\
\hline Herd size & $\begin{array}{l}\text { Increase by } 3 \text { improved breed cows for low maize potential } \\
\text { farms; increase by } 2 \text { improved breed cows for medium } \\
\text { and high maize potential farms. This is parameterized } \\
\text { using improved breed statistics in the data. }\end{array}$ \\
\hline
\end{tabular}

Note: All changes are relative to RAP 4 and RAP 5 production systems. 
Table 26. Average fertilizer application $(\mathrm{Nkg} / \mathrm{ha})$.

\begin{tabular}{lcc}
\hline Strata & RAP 4 and RAP 5* & $\begin{array}{c}\text { With } \\
\text { Intervention }\end{array}$ \\
\hline Low & 16.6 & 41.6 \\
Low-milk & 19.0 & 44.0 \\
Medium & 49.2 & 74.2 \\
Medium-milk & 52.8 & 77.8 \\
High & 56.2 & 81.2 \\
High-milk & 59.3 & 84.3 \\
\hline
\end{tabular}

Note: *Application is same in both.

This table also shows the fertilizer application under RAP 4 and RAP 5 for comparison. Based on the CTWN analysis, the increased $\mathrm{N}$ is expected to increase maize yields in each of the MPZs. In particular, the CTWN for the DSSAT model indicates that the maize yields increase up to approximately $180 \mathrm{~N} \mathrm{~kg} / \mathrm{ha}$ in the high MPZs, $100 \mathrm{Nkg} / \mathrm{ha}$ in the medium MPZs, and $60 \mathrm{~N} \mathrm{~kg} / \mathrm{ha}$ in the low MPZs. As Table 26 shows, this intervention does not push application rates up to these levels, on average. Higher application rates than those modeled in this analysis may go beyond the confidence of the crop model response shape to $\mathrm{N}$ fertilization in the high and medium MPZs. Moreover, in the low MPZs, the lack of water may have much more limitation on yields as $\mathrm{N}$ fertilization increases. Also, in the CTWN for the low MPZs, the crop models, DSSAT and APSIM, show some disagreement in yield response to higher $\mathrm{N}$ levels. For these reasons, $25 \mathrm{~N} \mathrm{~kg} / \mathrm{ha}$ is considered a reasonable increase in fertilizer application for this technological intervention.

\section{Crop simulation results}

The DSSAT crop model is used to predict the maize yield changes corresponding to the technological intervention described above in Table 25. The farm-level yields are simulated for each year in the future period under the future management developed in each RAP (CM5 crop simulation) and under management representing the intervention (CM6 crop simulation). These simulations are performed for each future climate scenario.

Table 27 shows the simulated relative yield statistics for each stratum across the GCMs of RAP 4. In the low MPZs, maize yields increase in each GCM as a result of the intervention. Based on the relative yield statistics, the average improvement ranges from $23 \%$ to $30 \%$ across the five GCMs, with the largest improvement occurring in the hot/wet scenario. The intervention improves yields in the medium MPZs, but to a lesser extent than in the low MPZs. The average relative yields range from 1.14 (hot/dry GCM) to 1.19 (cool/wet) in the medium MPZs (see Table 27). 
Table 27. DSSAT relative yields by Maize Potential Zone (MPZ), RAP 4 (RCP 4.5).

\begin{tabular}{|c|c|c|c|c|c|c|c|}
\hline & & \multicolumn{2}{|c|}{ Low Potential } & \multicolumn{2}{|c|}{ Medium Potential } & \multicolumn{2}{|c|}{ High Potential } \\
\hline & & Mean & CV (\%) & Mean & $\mathrm{CV}(\%)$ & Mean & CV $(\%)$ \\
\hline \multirow[t]{5}{*}{ GCM characterization } & Cool/wet & 1.27 & 26.7 & 1.19 & 13.1 & 1.17 & 13.7 \\
\hline & Cool/dry & 1.24 & 26.3 & 1.16 & 12.6 & 1.14 & 12.5 \\
\hline & Middle & 1.23 & 25.3 & 1.16 & 14.7 & 0.98 & 26.6 \\
\hline & Hot/wet & 1.30 & 27.2 & 1.18 & 13.8 & 1.16 & 13.6 \\
\hline & Hot/dry & 1.24 & 26.5 & 1.14 & 13.1 & 1.11 & 11.1 \\
\hline
\end{tabular}

Table 28. DSSAT relative yields by Maize Potential Zone (MPZ), RAP 5 (RCP 8.5).

\begin{tabular}{|c|c|c|c|c|c|c|c|}
\hline & & \multicolumn{2}{|c|}{ Low Potential } & \multicolumn{2}{|c|}{ Medium Potential } & \multicolumn{2}{|c|}{ High Potential } \\
\hline & & Mean & $\mathrm{CV}(\%)$ & Mean & $\mathrm{CV}(\%)$ & Mean & $\mathrm{CV}(\%)$ \\
\hline \multirow[t]{5}{*}{ GCM characterization } & Cool/wet & 1.74 & 35.0 & 1.33 & 18.5 & 1.30 & 18.5 \\
\hline & Cool/dry & 1.67 & 35.5 & 1.30 & 18.3 & 1.27 & 18.0 \\
\hline & Middle & 1.67 & 33.1 & 1.29 & 19.0 & 1.21 & 15.0 \\
\hline & Hot/wet & 1.81 & 33.9 & 1.34 & 20.1 & 1.28 & 18.5 \\
\hline & Hot/dry & 1.65 & 33.0 & 1.28 & 18.5 & 1.15 & 12.0 \\
\hline
\end{tabular}

The high MPZ exhibits more variation in average relative yields across the future climate scenarios. The intervention is predicted to decrease yields by $2 \%$, on average, in the middle GCM; while in the other GCMs, the yields are predicted to increase up to $17 \%$ from the intervention.

The intervention relative yield statistics for RAP 5 are summarized in Table 28. This table displays the mean and $\mathrm{CV}$ of the relative yields resulting from the intervention for each MPZ and future climate scenario. In general, the intervention positively impacts yields in the future climate scenarios of RAP 5, regardless of the MPZ. The crop model predicts that the intervention average relative yields range from 1.65 to 1.81 in the low MPZs, 1.28 to 1.34 in the medium MPZs, and 1.15 to 1.30 in the high MPZs. These ranges are over the five future climate scenarios associated with RAP 5 (RCP 8.5). In each of the MPZs, the lowest relative yield occurs in the hot/dry GCM.

According to the DSSAT model simulations, the intervention is predicted to improve maize yields in the future scenarios of RAP 4 and RAP 5. The only exception occurs for the high MPZ in the middle GCM of RAP 4, where the relative yield is 0.98. In all other combinations of MPZs and climate scenarios, the intervention improves maize yields, thereby offsetting negative climate impacts on yields. There also appears to be heterogeneity in the impacts of the intervention on maize yields 
across the MPZs and across the RAPs. In both RAPs, the low MPZs have the largest increases in maize yields across the climate scenarios. For all MPZs, the improvement in maize yields tends to be higher in RAP 5 than in RAP 4. This implies that the intervention may have a larger impact in RAP 5, where predicted climate impacts on maize yields are more negative than in RAP 4.

\section{Economic analysis}

The economic impacts of the intervention in future scenarios are estimated using the TOA-MD model. In this analysis, system 1 is represented by farm production in future scenarios without the intervention and system 2 represents production with the technological intervention. Each system is modeled uniquely for each RAP, GCM, and price scenario. The price scenarios are the same as those used in the Core Question 3 analysis. The TOA-MD model calculates the distributional impacts of the intervention by comparing the distribution of farm net returns for each system.

The system 1 parameter calculations are described in the Core Question 3 analysis. The economic differences between the two systems are the maize and milk net returns. For system 2, the maize net returns are based on simulated yield changes that result from the technological intervention in each future scenario. As such, the maize net returns for system 2 are calculated using the intervention relative yields and applying the relative yield method to system 1 maize net returns. The milk net returns under the intervention are calculated as the net returns of the additional improved breed cows plus the milk net returns from system 1 . The additional cow net return parameters are approximated for each farm using the improved breed statistics from the current period and the milk production trends for each RAP.

For Core Question 4, which takes place in the future world, the average milk net returns from the new cows are calculated using the Table 18 parameters and the milk yield, price, and cost trends from Table 15. The analysis is done under the assumption that each farm activity is impacted by climate to the same degree as maize. To account for this, the strata average maize relative yield from Core Question 3 (i.e., the climate relative yield) is applied to the average milk production of the additional cows in each future scenario. The standard deviation of milk net returns with the intervention is approximated by assuming that the CV of milk net returns is $115 \%$ in the low MPZs and $110 \%$ in the medium and high MPZs.

In general, across both the future and current scenarios, the calculated CVs in each MPZ are similar to the assumed values under the intervention. This analysis assumes that the correlation between net returns in system 1 and system 2 is 0.85 . Given this high correlation and the fact that average net returns for both maize and milk are higher in system 2, the predicted adoption rate can be considered an upper bound adoption rate. 
The range of impacts of the technological intervention in RAP 4 scenarios is shown in Table 23. This table shows outcomes from the scenario with lowest percentage of households adopting the intervention and the scenario with the highest percentage of households adopting the intervention. Across the RAP 4 climate and price scenarios, between $77.1 \%$ (middle GCM and high price scenario) and $78.7 \%$ (cool/wet GCM and high price scenario) of all households are predicted to adopt the intervention. In other words, the intervention is predicted to increase farm net returns for approximately three-fourths of farms across Kenya in RAP 4 scenarios. Furthermore, per capita income increases, and poverty decreases as a result of the intervention. The strata-level results show some heterogeneity but are largely consistent with the aggregate results. A higher percentage of households is predicted to adopt the intervention in the low MPZs than in the other areas of Kenya. Moreover, farms in the low MPZs have the largest percentage increases in net returns and per capita income.

The RAP 4 results can be analyzed further by looking at the activity-specific impacts of the intervention. Table 22 shows the changes in average maize and milk net returns from the intervention for the cool/wet high price scenario (the scenario with the highest adoption rate). These changes are based on the average net returns when all farms are participating in the intervention. First, this table indicates that the maize net returns increase in each stratum. These increases are the result of higher maize yields predicted with the intervention. Average milk net returns also increase for each stratum. The increases in milk net returns are considerably larger than the increases in maize net returns, in terms of absolute and percentage changes.

There are two reasons for the large increases in milk net returns. First, without the intervention, average number of cows per farm is between 1 and 3 in RAP 4 across all the MPZs (average herd size range is 4-9 total cattle). As such, adding 2-3 cows per farm is, in many cases, doubling the number of cows used in milk production. The second reason is that the additional cows are improved breeds and, as such, are more productive and profitable than existing local and cross breeds that many farms own.

These factors, taken together, explain why this intervention is predicted to increase milk net returns by large amounts across all the MPZs in Kenya. The changes in average milk net returns are largest in the low MPZs. This is the result of these farms receiving one more cow than the other MPZs. Moreover, additional cows are more profitable in the low MPZs because milk prices are higher in these locations. Current milk prices are highest in the low MPZs and this price difference is assumed to carry over into the future scenarios modeled in this study.

The results from the RAP 5 economic simulations are shown in Table 29. This table shows the results for the scenarios with the lowest and highest aggregate intervention adoption rates. In the hot/dry GCM and high price scenario, $81.0 \%$ of 
Table 29. Range of economic results - impact of technological intervention, RAP 5.

\begin{tabular}{|c|c|c|c|c|c|c|c|c|c|c|c|c|}
\hline \multirow[b]{3}{*}{ Strata } & \multicolumn{6}{|c|}{ Lowest \% Better Off } & \multicolumn{6}{|c|}{ Highest $\%$ Better Off } \\
\hline & \multirow[b]{2}{*}{ GCM } & \multirow[b]{2}{*}{$\begin{array}{l}\text { Price } \\
\text { Sce- } \\
\text { nario }\end{array}$} & \multirow{2}{*}{$\begin{array}{l}\text { Interventior } \\
\text { Adoption } \\
\text { Rate (\%) }\end{array}$} & \multirow{2}{*}{$\begin{array}{c}\text { Change } \\
\text { n in Net } \\
\text { Returns } \\
(\%)\end{array}$} & \multirow[b]{2}{*}{$\begin{array}{c}\text { Change } \\
\text { in PCI } \\
(\%)\end{array}$} & \multirow{2}{*}{$\begin{array}{c}\text { Change } \\
\text { in } \\
\text { Poverty } \\
\text { Rate } \\
(\%)\end{array}$} & \multirow[b]{2}{*}{ GCM } & \multirow[b]{2}{*}{$\begin{array}{l}\text { Price } \\
\text { Sce- } \\
\text { nario }\end{array}$} & \multirow[b]{2}{*}{$\begin{array}{l}\text { Interventio } \\
\text { Adoption } \\
\text { Rate (\%) }\end{array}$} & \multirow{2}{*}{$\begin{array}{c}\text { Change } \\
\text { n in Net } \\
\text { Returns } \\
(\%)\end{array}$} & \multirow{2}{*}{$\begin{array}{c}\text { Change } \\
\text { in PCI } \\
(\%)\end{array}$} & \multirow{2}{*}{$\begin{array}{c}\text { Change } \\
\text { in } \\
\text { Poverty } \\
\text { Rate } \\
(\%)\end{array}$} \\
\hline & & & & & & & & & & & & \\
\hline Low & Hot/dry & High & 86.9 & 276 & 95.2 & -19.4 & Cool/wet & Low & 85.8 & 315 & 98.0 & -21.5 \\
\hline Low-milk & Hot/dry & High & 84.2 & 179 & 73.8 & -11.3 & Cool/wet & Low & 83.4 & 209 & 80.7 & -12.6 \\
\hline Medium & Hot/dry & High & 82.1 & 57 & 34.8 & -11.7 & Cool/wet & Low & 85.4 & 68 & 37.9 & -13.3 \\
\hline Medium-milk & Hot/dry & High & 74.7 & 39 & 25.1 & -5.9 & Cool/wet & Low & 77.8 & 45 & 27.1 & -6.8 \\
\hline High & Hot/dry & High & 85.9 & 81 & 33.2 & -13.7 & Cool/wet & Low & 89.6 & 106 & 42.7 & -16.9 \\
\hline High-milk & Hot/dry & High & 80.0 & 44 & 22.5 & -7.3 & Cool/wet & Low & 84.4 & 55 & 27.3 & -8.5 \\
\hline Aggregate & Hot/dry & High & 81.0 & 75 & 40.3 & -10.7 & Cool/wet & Low & 83.2 & 90 & 44.4 & -12.2 \\
\hline
\end{tabular}


Table 30. Impact of technological intervention on average maize and milk net returns - RAP 5 .

\begin{tabular}{|c|c|c|c|c|c|c|}
\hline \multirow[b]{2}{*}{ Strata } & \multirow[b]{2}{*}{ GCM } & \multirow[b]{2}{*}{ Price Scenario } & \multicolumn{2}{|c|}{$\begin{array}{c}\text { Change in } \\
\text { Maize Net } \\
\text { Returns }\end{array}$} & \multicolumn{2}{|c|}{$\begin{array}{l}\text { Change in } \\
\text { Milk Net } \\
\text { Returns }\end{array}$} \\
\hline & & & (Ksh) & $(\%)$ & (Ksh) & $(\%)$ \\
\hline Low & Cool/wet & Low & 7085 & 70.0 & 16,7088 & - \\
\hline Low-milk & Cool/wet & Low & 5071 & 45.3 & 18,5210 & 736.3 \\
\hline Medium & Cool/wet & Low & 3163 & 33.6 & 61067 & - \\
\hline Medium-milk & Cool/wet & Low & 3319 & 30.0 & 62459 & 333.9 \\
\hline High & Cool/wet & Low & 8228 & 24.8 & 52602 & - \\
\hline High-milk & Cool/wet & Low & 13657 & 26.2 & 54864 & 212.4 \\
\hline
\end{tabular}

all households have higher net returns with the intervention, while in the cool/wet GCM and low price scenario, $83.2 \%$ of all households have higher net returns with the intervention. Similar to the RAP 4 results, the intervention is beneficial for a large portion of households, increases per capita income, and decreases poverty. Within each stratum, three-quarters or more of the households adopt the intervention. The largest increases in farm net returns occur for those in the low MPZs. Moreover, within each MPZ, farms without milk before the intervention tend to benefit more than those with milk before the intervention.

Table 30 displays the intervention impacts on average maize and milk net returns for the scenario with the highest intervention adoption rate. These impacts reflect changes in average net returns when all farms are participating in the intervention. For each stratum, maize net returns increase as a result of the intervention in this scenario. These increases are the result of higher maize yields predicted with the intervention. The percentage increase in maize net returns is highest in the low MPZs, which is consistent with these farms having the highest intervention relative yields in RAP 5 climate scenarios (Table 28).

Milk net returns also increase for each stratum and, similar to RAP 4, the increases in milk net returns are considerably larger than the increases in maize net returns. The reasons for the size of the increases in milk net returns are, like RAP 4, related to the herd sizes and the productivity of improved breed cows. Average herd sizes without the intervention are 1-2 cows (3-7 total cattle) with a mixture of local, cross, and improved breeds. As such, the addition of 2-3 improved breed cows has a large impact on milk net returns by increasing both total production and productivity. The impact on milk net returns is highest in low MPZs. This outcome occurs for similar reasons as in RAP 4: farms in the low MPZs receive more cows with the intervention and have higher milk prices compared to farms in the other MPZs. 
The economic simulation predicts that the intervention improves the economic well-being of a large majority of Kenyan farms in the future scenarios. Specifically, the intervention increases farm net returns, which increases per capita income and decreases poverty across Kenya in each of the future scenarios.

There are two avenues by which the intervention affects farms. First, the intervention offsets negative climate impacts on maize productivity by increasing fertilizer and manure application. Moreover, in RAP 5, maize productivity is improved due to soil restoration practices. These productivity improvements lead to increases in maize net returns in each MPZ.

Second, the intervention includes the provision of 2-3 improved breed cows to each farm which roughly doubles the number of cows available for milk production. In addition, these cows are generally more productive and profitable than the local and cross breeds commonly used by farms in Kenya. As such, the intervention leads to large increases in milk net returns. In fact, the changes in milk net returns outweigh those in maize net returns and are the main drivers in the positive outcomes associated with the intervention.

These results suggest that the policy interventions aimed at increasing the farms' focus on milk production, including the use of improved breeds, have the potential to greatly improve livelihoods in future maize-based systems of Kenya.

\section{Conclusions}

This RIA provides a number of insights into the potential impact of climate change and adaptation on maize-based systems in Kenya. First, all the climate models predict a warmer future compared to the current climate; and, the future scenarios are warmer in the higher emissions pathway. The projected increase in temperature is lowest at the coast and increases westward, with the largest increases at the sites near the Kenya-Uganda border. The climate models are in less agreement on the direction of change in precipitation compared to current levels. Under both emissions scenarios, the wettest scenarios indicate increases in precipitation and the driest scenarios predict decreases in precipitation during the growing season. Based on previous work, there is reason to believe that climate models have relatively low skill in reproducing East Africa precipitation climatology which leads to uncertainty as to whether the region will be wetter or drier in the future (Yang et al., 2015).

This assessment finds that projected climate change in Kenya negatively impacts current maize-based systems. Crop model simulations indicate that, with current management, the maize yields are lower in future climate scenarios compared to current climate. The decrease in maize yields leads to lower farm net returns for a majority of farms across the future climate scenarios and across the maize producing 
regions of Kenya. However, there is heterogeneity in the impacts across Kenya: the farms in the high MPZ are potentially the most vulnerable to climate change. In the worst case climate scenario, maize yields in this area are predicted to decrease by a larger degree than in the low and medium MPZs. Moreover, farms in the high MPZs are more reliant on maize than the other MPZs, where household income is relatively diversified across off-farm work, maize, other crops, and livestock.

In terms of potential adaptation, a large portion of farms in the current maizebased systems may benefit from a policy intervention aimed at decreasing fertilizer prices and increasing milk productivity. This intervention is represented by a subsidy that lowers the prices farmers pay for commercial fertilizers and improves access to fertilizers with investment in infrastructure and lowering of transactions costs associated with participating in fertilizer markets. The technological intervention also includes technical assistance programs to improve feeding strategies for milking cows and the donation of one improved breed milking cow to every farm, similar to the basic elements of the EADD project (EADD 2013, 2014). Both maize and milk productivity are predicted to increase under the intervention, which leads to increases in farm net returns for households across Kenya. By increasing farm net returns, the intervention is expected to increase the per capita income and decrease the poverty rate.

The findings in regard to climate impact on future maize-based systems illustrate the importance of examining both biophysical and economic changes that result from climate change. From a biophysical standpoint, the DSSAT crop model predicts that maize yields under future management (as developed for each RAP) are negatively impacted by climate across Kenya in a number of RAP 4 scenarios and most RAP 5 scenarios. However, these lower yields do not necessarily lead to negative economic impacts because, according to the global economic model (IMPACT), prices in climate change scenarios are predicted to be higher than prices in scenarios without climate change. As such, the economic impacts of climate change are the result of both biophysical and economic changes that occur with climate change.

In this assessment, the higher prices with climate change tend to offset the negative climate impact on yields, leading to aggregate predictions of positive net impacts on mean farm net returns, increases in the per capita income, and decreases in poverty across the future scenarios. However, in the high MPZ, the range of outcomes includes negative net economic impacts from climate change. First, these farms are predicted to be the most negatively impacted from a biophysical standpoint in the worst-case scenarios, and second, they obtain the most income from maize, which has relatively smaller price increase with climate change than the price increases for other crops.

When combined, these two factors yield predictions of lower farm net returns and a majority of households being worse off with climate change in the high 
MPZ. Despite the aggregate outcomes, the strata-level results predict that the climate impacts differ based on location agroecology and household income diversification.

As in current production systems, a large majority of farms in future production systems are predicted to benefit from a policy intervention aimed at increasing fertilizer application and milk production. This intervention is modeled with increased fertilizer and manure application and the provision of 2-3 improved breed cows to each farm in future production systems. The changes in maize management increase yields and offset negative climate impacts. The provision of multiple improved breed cows increases both milk production and milk productivity. As a result, maize and milk net returns tend to increase for farms across Kenya, leading to increases in the per capita income and decreases in the poverty rates in each of the future scenarios. The large increase in milk net returns is the main driver in the positive outcomes associated with the intervention. This result suggests that the policy interventions aimed at increasing the farms' focus on milk production, including the use of improved breeds, have the potential to greatly improve livelihoods in future maize-based systems of Kenya.

\section{Acknowledgments}

Some of the data used in this work were collected and made available by the Tegemeo Institute of Agricultural Policy and Development of Egerton University, Kenya. However, the specific findings and recommendations remain solely the authors' and do not necessarily reflect those of Tegemeo Institute.

\section{References}

AgMIP. 2018. AgMIP Protocols for Regional Integrated Assessments. Version 7. https://agmip.or g/wp-content/uploads/2018/08/AgMIP-Protocols-for-Regional-Integrated-Assessment-v7 -0-20180218-1-ilovepdf-compressed.pdf

Antle, J.M. 2011. Parsimonious multi-dimensional impact assessment. Am. J. Agric. Econ., 93(5): 1292-1311.

Antle, J.M. and Valdivia, R.O. 2006. Modeling the supply of ecosystem services from agriculture: A minimum-data approach. Aust. J. Agric. Resour. Econ., 50(1): 1-15.

Antle, J.M., Valdivia, R.O. et al. 2015. AgMIP's transdisciplinary agricultural systems approach to regional integrated assessment of climate impacts, vulnerability, and adaptation. In C. Rosenzweig and D. Hillel (eds.), Handbook of Climate Change and Agroecosystems: The Agricultural Model Intercomparison and Improvement Project (AgMIP), pp. 27-44. ICP Series on Climate Change Impacts, Adaptation, and Mitigation Vol. 3. Part 1, Imperial College Press, doi:10.1142/9781783265640_0002.

Central Bank of Kenya, 2017. Foreign Exchange Rates. https://www.centralbank.go.ke/rates/forex -exchange-rates/ 
Claessens, L., Antle, J.M. et al. 2012. A method for evaluating climate change adaptation strategies for small-scale farmers using survey, experimental and modeled data. Agric. Syst., 111: $85-95$.

Claessens, L., Antle, J.M. et al. 2015. Scoping climate change adaptation strategies for smallholder farmers in East Africa - A multi-dimensional, multi-scenario impact assessment. In N.P. Singh, C. Bantilan, K. Byjesh, and S. Nedumaran (eds.), Climate Change Challenges and Adaptations at Farm-level: Case Studies from Asia and Africa, Edition: CABI Climate Change Series, CABI. doi: 10.1079/9781780644639.0138.

Claessens, L., Gummadi, S. et al. 2017. Final technical report AgMIP East Africa. Part II: Methods and Technical Findings. Available on request.

EADD, 2013. Gender, dairy production and marketing: Baseline surveys report: Report 6 . Nairobi, Kenya: East Africa Dairy Development Project (EADD). http://hdl.handle.net/105 $68 / 34456$

EADD, 2014. East Africa Dairy Development (EADD) II: Sustainable Livelihoods for One Million People in Uganda, Kenya and Tanzania by 2018. http://www.heifer.org/eadd/

Government of Kenya, 2013. Vision 2030 The Popular Version. www.vision2030.go.ke

Herrero, M., Fawcett, R.H. et al. 2002. Predicting Intake and Nutrient Supply of Tropical and Temperate Diets for Ruminants Using a Simple Dynamic Model of Digestion. Bioparametrics Ruminant Nutrition Reference Laboratories Monograph, Institute of Ecology and Resource Management, University of Edinburgh, UK.

IPCC, 2014. Climate Change 2014: Synthesis Report. Contribution of Working Groups I, II and III to the Fifth Assessment Report of the Intergovernmental Panel on Climate Change, p. 151. [Core Writing Team, R.K. Pachauri and L.A. Meyer (eds.)]. IPCC, Geneva, Switzerland.

O'Neill, B.C., Kriegler, E. et al. 2015. The roads ahead: Narratives for shared socioeconomic pathways describing world futures in the 21st century. Glob. Environ. Change, 42: 169-180. doi:10.1016/j.gloenvcha.2015.01.004.

Robinson, S., Mason d'Croz, D. et al. 2015: The International Model for Policy Analysis of Agricultural Commodities and Trade (IMPACT): Model description for version 3. IFPRI Discussion Paper 1483. Washington, D.C.: International Food Policy Research Institute (IFPRI). http://ebrary.i fpri.org/cdm/ref/collection/p15738coll2/id/129825

Rosenzweig, C., Jones, J.W. et al. 2013. The Agricultural Model Intercomparison and Improvement Project (AgMIP): Protocols and pilot studies. Agric. For. Meteorol., 170: 166-182. http://dx.d oi.org/10.1016/j.agrformet.2012.09.011

Shikuku, K.M., Valdivia, R.O. et al. 2017. Prioritizing climate-smart livestock technologies in rural Tanzania: A minimum data approach. Agric. Syst., 151: 204-216. https://doi.org/10.1016/j.ag sy.2016.06.004

Tegemeo Institute, 2007. Rural Household Indicator Survey. Tegemeo Agricultural Policy Research and Analysis, Egerton University.

Valdivia, R.O., Antle, J.M. et al. 2015. Representative Agricultural Pathways and Scenarios for Regional Integrated Assessment of Climate Change Impacts, Vulnerability, and Adaptation. In C. Rosenzweig and D. Hillel (eds.), Handbook of Climate Change and Agroecosystems: The Agricultural Model Intercomparison and Improvement Project (AgMIP), pp. 101-145. ICP Series on Climate Change Impacts, Adaptation, and Mitigation Vol. 3. Part 1, Imperial College Press, doi: 10.1142/9781783265640_0005.

Valdivia, R.O. 2016. Is Sustainable Development of Semi-Subsistence Mixed Crop-Livestock Systems Possible? An Integrated Assessment of Machakos, Kenya. Wageningen University. Wageningen

Wiebe, K., Lotze-Campen, H. et al. 2015. Climate change impacts on agriculture in 2050 under a range of plausible socioeconomic and emissions scenarios. Environ. Res. Lett., 10(8): 085010. https://doi.org/10.1088/1748-9326/10/8/085010 
World Bank. 2009. Kenya - Poverty and Inequality Assessment: Executive Summary and Synthesis Report. Washington, DC: World Bank. http://documents.worldbank.org/ curated/en/425611468089394594/Kenya-Poverty-and-inequality-assessment-executive-sum mary-and-synthesis-report

Yang, W., Seager, R. et al. 2015. The Rainfall Annual Cycle Bias over East Africa in CMIP5 Coupled Climate Models. J. Clim., 28(24): 9789-9802. https://doi.org/10.1175/JCLI-D-15-0323.1 